\title{
Formal Description of Mesozoic and Cenozoic Biotas Found from Pakistan
}

\author{
Muhammad Sadiq Malkani \\ Geological Survey of Pakistan, Muzaffarabad, Pakistan \\ Email:malkanims@yahoo.com
}

How to cite this paper: Malkani, M.S. (2021) Formal Description of Mesozoic and Cenozoic Biotas Found from Pakistan. Open Journal of Geology, 11, 411-455. https://doi.org/10.4236/ojg.2021.119023

Received: August 27, 2021

Accepted: September 23, 2021

Published: September 26, 2021

Copyright (c) 2021 by author(s) and ScientificResearch Publishing Inc.

This work is licensed under the CreativeCommons Attribution International License (CC BY 4.0).

http://creativecommons.org/licenses/by/4.0/

\section{(c) (i) Open Access}

\begin{abstract}
During the early two decades of third millennium, many Mesozoic and Cenozoic biotas belong to plesiosaur, Titanosauriformes, titanosaurs, theropods, Mesoeucrocodiles, pterosaur, bird, snake, fishes, mammals, eucrocodiles, invertebrates and plants from Pakistan were found. Previously a few were formally published according to nomenclatural rules. Most of the Mesozoic vertebrates were formally published in August 2021, and the remaining Mesozoic and Cenozoic biotas are being formally described here.
\end{abstract}

\section{Keywords}

Mesozoic, Cenozoic, Biotas, Footprints, Trackways, Archosaurs, Pakistan

\section{Introduction}

Mesozoic and Cenozoic vertebrates, invertebrates and plants fossils [1]-[6] were discovered since 2000. Majority of the Mesozoic biotas were found from the Balochistan Province, while some were from South Punjab (Saraikistan), North Punjab and Sindh. Further footprints and trackways of archosaurs were discovered from the North Punjab, South Punjab (Saraikistan) and Balochistan, Pakistan. Some Mesozoic vertebrates were formally described during August 2021. While the remaining biotas of Mesozoic and Cenozoic eras are being formally described here.

Institutional Abbreviation. GSP, Geological Survey of Pakistan, Quetta, Pakistan.

\section{Materials and Methods}

The materials belong to compiled data from previous work especially mentioned in references and also new field materials collected by present author during 
numerous field seasons regarding the lithology, stratigraphy and paleontology of Pakistan. The methods applied here are many disciplines of purely geological and paleontological methods and description.

\section{Results and Discussion}

Here the results and discussion are represented as the Mesozoic and Cenozoic biotas belong to Titanosauriformes, titanosaurs, theropods, Mesoeucrocodiles, pterosaur, bird, snake, plesiosaur, fishes, mammals, eucrocodiles, invertebrates and plants from Pakistan, and footprints and trackways of ornithischian, sauropods, theropods and pterosaurs were found from Pakistan.

\subsection{Brohisaurus kirthari Titanosauriform from Late Jurassic of Pakistan}

Brohisaurus kirthari titanosauriform was formally described in 2003 [7] although holotype was not well figured with fossil number which were resolved in 2021 [1].

\subsection{Poripuchia (Titanosauria, Sauropoda) Found from Pakistan}

The latest Cretaceous titanosaur fossils (about 3000 banes/pieces of bones) were found from about 25 localities and also 9 promising localities (Figure 1) (Figure 4 of [1]) expected in a block (about $50 \mathrm{~km}$ north south and $80 \mathrm{~km}$ east west) located in Koh Sulaiman area of middle Indus/Sulaiman basin (Balochistan and South Punjab, Pakistan) and only a few fossils from Kirthar Range (Figure 1) of lower Indus/south Indus/Kirthar basin (Balochistan and Sindh Provinces, Pakistan) [1] [2] [3] [4] [8]. An extended abstract [9] including new names like Balochisaurus malkani, Marisaurus jeffi, Pakisaurus balochistani, Sulaimanisaurus gingerichi and Khetranisaurus barkhani titanosaurian sauropods and Vitakridrinda sulaimani theropod was submitted in 2003 for $5^{\text {th }}$ Pakistan Geological Congress and later on papers [7] [10] [11] were submitted for Geological Bulletin, University of Peshawar, Pakistan. Meanwhile the $5^{\text {th }}$ Pakistan Geological Congress 2003 was shifted from 2003 to 2004. Consequently the conference paper [9] was appear later from the papers published in Geological Bulletin, University of Peshawar [7] [10] [11]. These conference taxa were informally published in 2006 [12] because there was no declaration of new names and type locality location, diagnosis and comparisons, etc were not properly mentioned. Again new names like Gspsaurus pakistani, Saraikimasoom vitakri and Nicksaurus razashahi were published in conference 2014 [13] and Maojandino alami was published in conference 2015 [14]. Later on these taxa were informally described in 2015 [15]. During 2020 the four titanosaur taxa like Gspsaurus pakistani [2], Saraikimasoom vitakri [3], Pakisaurus balochistani [4] and Sulaimanisaurus gingerichi [4] were recognized and described. Before $5^{\text {th }}$ August 2021, all of above mentioned titanosaur taxa were informal because of many nomenclatural issues regarding International Code of Zoological nomenclature (ICZN) 
rules. Consequently many archosaurs were formally described in August 2021 including Gspsaurus pakistani, Saraikimasoom vitakri, Pakisaurus balochistani, Sulaimanisaurus gingerichi and Khetranisaurus barkhani. Here the formal description of Balochisaurus malkani, Nicksaurus razashahi, Maojandino alami and Marisaurus jeffi along with other Mesozoic and Cenozoic biotas are being presented. Further here fossils are properly being referred to these formally published taxa [1] like Gspsaurus pakistani (Figures 2-5), Saraikimasoom vitakri (Figures 5-8) and Pakisaurus balochistani (Figure 9).

\subsubsection{Balochisaurus malkani Balochisaurid Poripuchian Titanosaur from Pakistan \\ Systematic paleontology}

Dinosauria; Saurischia; Sauropoda; Titanosauriformes; Titanosauria; Poripuchia [1];

Balochisauridae new family (features same as type species)

Definition: Balochisauridae characterized by biconvex first caudal, strong ventral reduction of width and length of midcaudals, robust rectangle shaped proximal femoral shaft and robust tilted subsquare/subrectangle shaped proximal tibia while Gspsauridae has lense shaped proximal tibia and Pakisauridae has flat proximal tibia. Tilted subsquare/subrectangle shaped proximal tibia and robust rectangle shaped proximal femoral shaft of Balochisauridae differentiates it also from Titanosauridae, Saltasauridae and Saltasaurinae.

Balochisaurus malkani new genus and new species (Figure 7)

Holotype: presacral vertebrae GSP/MSM-126-15 to GSP/MSM-130-15, GSP/ MSM-822-15 to GSP/MSM-824-15, and GSP/MSM-818-15; Caudal vertebrae GSP/MSM-43-15, GSP/MSM-44-15, GSP/MSM-44a-15, GSP/MSM-45-15 to GSP/MSM-48-15, GSP/MSM-260-15, GSP/MSM-505-15, GSP/MSM-834-15 and GSP/MSM-325-15; cervical rib GSP/MSM-881-15; caudal inclined posteriorly neural spine GSP/MSM-324-15; distal rib/neural spine GSP/MSM-672-15, GSP/ MSM-1056-15; proximal rib of dorsal vertebra GSP/MSM-322-15; dorsal neural spine with post zygapophyses and prespinal laminae of dorsal vertebra GSP/ MSM-323-15; mid rib GSP/MSM-531-15 of dorsal vertebra; left anterior sternal GSP/MSM-675-15; left proximal humerus GSP/MSM-245-15; distal left humerus GSP/MSM-174-15; left proximal ulna GSP/MSM-78-15;proximal metacarpal GSP/MSM-297-15; distal metacarpal GSP/MSM-750-15; left acetabulum GSP/ MSM-166-15; left proximal femur GSP/MSN-168-15; distal left femur GSP/ MSM-173-15; proximal left tibia GSP/MSM-246-15; distal tibia/ulna? GSP/ MSM-227-15 (Figure 7). It can also be seen in Figure 7 \& Figure 8 of [3]. All the holotypic materials seem to be associated as one individual due to same time and surface findings in the same formation, same locality and fit size. Duplication is only femoral bones which have same features like holotype. The holotypic materials are found on 3 sites. The northern site yielded a few bones, middle site yielded majority of bones and southern site yielded only a complete femur. The northern and southern sites are about 50 meters/m away from middle site. These 
fossils are housed in the museum of Geological Survey of Pakistan, Quetta.

Type locality, horizon and age: Holotype was found in Mari Bohri 15 (latitude $29^{\circ} 41^{\prime} 57^{\prime \prime N}$; longitude $69^{\circ} 14^{\prime} 59^{\prime \prime E}$ ) (Figure 1), Barkhan district, Balochistan. Host horizon is the Vitakri Formation of Fort Munro Group [1] [8] [16]. The lateral and vertical lithological variations and distribution of Vitakri Formation were discussed in [1] [4] [17]. Age of Vitakri Formation is latest Maastrichtian [4] [12].

Etymology: Genus Balochi, honors host Balochi tribe, and saurus, Greek for reptile. Species malkani, honoring the Malkani Tribe living in the host Koh Sulaiman and other parts of Indo-Pakistan (not on author name). Like this many host tribes Khetran, Baloch, Mari, Bugti, Buzdar, Brohi, Zahri, Malakhel, etc. were honored.

Diagnosis: Balochisaurus malkani sharing with Titanosauria as procoelous caudals (except first biconvex caudal), forward insertion of neural arches on caudals, prominent olecranon process on ulna and vertebrae lacking hyposphene-hypantrum articulations. Balochisaurus malkani shares with Poripuchia on basis of procoelous distal and distalmost caudals. It shares with Gspsauridae on the basis of ratio of transverse dorsal width to the transverse ventral width is about 1.5. It shares with Saraikimasoominae on the basis of ratio of transverse dorsal width to the transverse ventral width is about 1.5 , and proximal stocky tibia with equal transverse and anteroposterior width. Balochisaurus malkani characterised as midcaudals with strongly reduced ventral view like Nicksaurus razashahi, while Marisaurus jeffi and Maojandino alami have relatively less ventral compression of caudals and Pakisaurus balochistani, Sulaimanisaurus gingerichi and Khetranisaurus barkhani have almost no ventral compression of caudals. Balochisaurus malkani has biconvex first caudal centrum, stocky rectangle shaped proximal femoral shaft, and tilted subsquare or rectangle shaped proximal tibia with equal transverse and anteroposterior widths while Maojandino has lense shaped proximal tibia and Pakisaurus and Sulaimanisaurus have transversely compressed flat proximal tibia.

Description: Balochisaurus malkani holotypic caudal vertebrae were described in conference 2004 [9] and informally in 2006 [12]. Its holotypic elements (other than holotypic vertebrae of [12]) from Mari Bohri and referred materials from different localities were described briefly in [8]. Its complete holotype was first figured as Figure 7 \& Figure 8 of [3]. Its updated description and comparisons can be seen in [3].

\subsubsection{Nicksaurus razashahi Titanosaur from the Vitakri Formation of Pakistan \\ Systematic paleontology}

Dinosauria; Saurischia; Sauropoda; Titanosauriformes; Titanosauria; Poripuchia [1]; Gspsauridae [1]; Saraikimasoominae [1].

Nicksaurus razashahi new genus and new species (Figure 6).

Holotype: Jaw ramus articulated with 6 teeth GSP/MSM-138-4n; cranial ma- 
terials and teeth fragments in matrix GSP/MSM-315-4n and GSP/MSM-314-4n; cervical vertebrae GSP/MSM-381-4n to GSP/MSM-383-4n; cervical/dorsal vertebra GSP/MSM-212-4n; caudal vertebrae GSP/MSM-347-4n and GSP/MSM-348-4n; caudal chevron GSP/MSM-313-4n; humerus parts GSP/MSM-380-4n, GSP/MSM377-4n, GSP/MSM-379-4n and GSP/MSM-438-4n; proximal radius GSP/MSM344-4n; spongy proximal pubis with glenoid surface GSP/MSM-1096-4n; left femur GSP/MSM-190-4n; right distal femur GSP/MSM-192-4n; right femur sections GSP/MSM-378-4n and GSP/MSM-270-4n; left and right distal tibiae GSP/MSM346-4n and GSP/MSM-345-4n (Figure 6) (Figure 3 of [3]). Holotype found at the same time as surface finds (only femur was partially excavated) in the same formation, same site, size matches and no duplication, all shows association of a single individual. Fossils are housed in museum of Geological Survey of Pakistan, Quetta.

Type locality, horizon and age: Holotype was found in north Kinwa 4 or $4 \mathrm{n}$ (latitude $29^{\circ} 41^{\prime} 16^{\prime \prime} \mathrm{N}$; longitude $69^{\circ} 23^{\prime} 31^{\prime \prime} \mathrm{E}$ ) (Figure 4 of [1]) of Vitakri dome area, Barkhan district, Balochistan. Host horizon is the Vitakri Formation of Fort Munro Group [1] [4] [8] [16] [17]. Age is latest Maastrichtian [4] [12].

Etymology: Genus Nick, honors the British Journalist Nicholas/Nick Allen who helped for preservation of dinosaur footprints from Pakistan, saurus, Greek for reptile. Species N. razashahi, honors Dr Raza Shah of Geological Survey of Pakistan.

Diagnosis: Nicksaurus razashahi medium sized sauropod shares with the Titanosauria as vertebrae lacking hyposphene-hypantrum articulations; procoelous caudals; and forward insertion of neural arches on caudals. It shares with Poripuchia because of sharing with Gspsauridae. It shares with Gspsauridae on the basis of ratio of transverse dorsal width to the transverse ventral width is about 1.5. It shares with Saraikimasoominae on the basis of ratio of transverse dorsal width to the transverse ventral width is about 1.5. Nicksaurus razashahi diagnosed as slender, circular or subcircular teeth with indices $3-5$, teeth converge/taper on all sides gradually toward tip (opposite of pakisaurids teeth (Figure 9) with constant thickness except tip); strongly reduced ventral caudals; transversely expanded oval shaped distal stocky tibia (unlike flat tibia of Pakisaurus balochistani and Sulaimanisaurus gingerichi).

Description: Nicksaurus razashahi holotypic material was first figured in conferences 2014 [13] and 2015 [14] and later on informally in 2015 [15]. Its teeth are elongated mostly conical i.e., decreasing diameter gradually from base to tip (while tooth of Pakisaurus balochistani (Figure 9) maintain almost same thickness possibly except on tip which is not preserved). Its updated description can be seen in [3].

\subsubsection{Maojandino alami Poripuchian Titanosaur from Pakistan Systematic paleontology}

Dinosauria; Saurischia; Sauropoda; Titanosauriformes; Titanosauria; Poripuchia [1]; Gspsauridae [1]; Gspsaurinae [1]. 


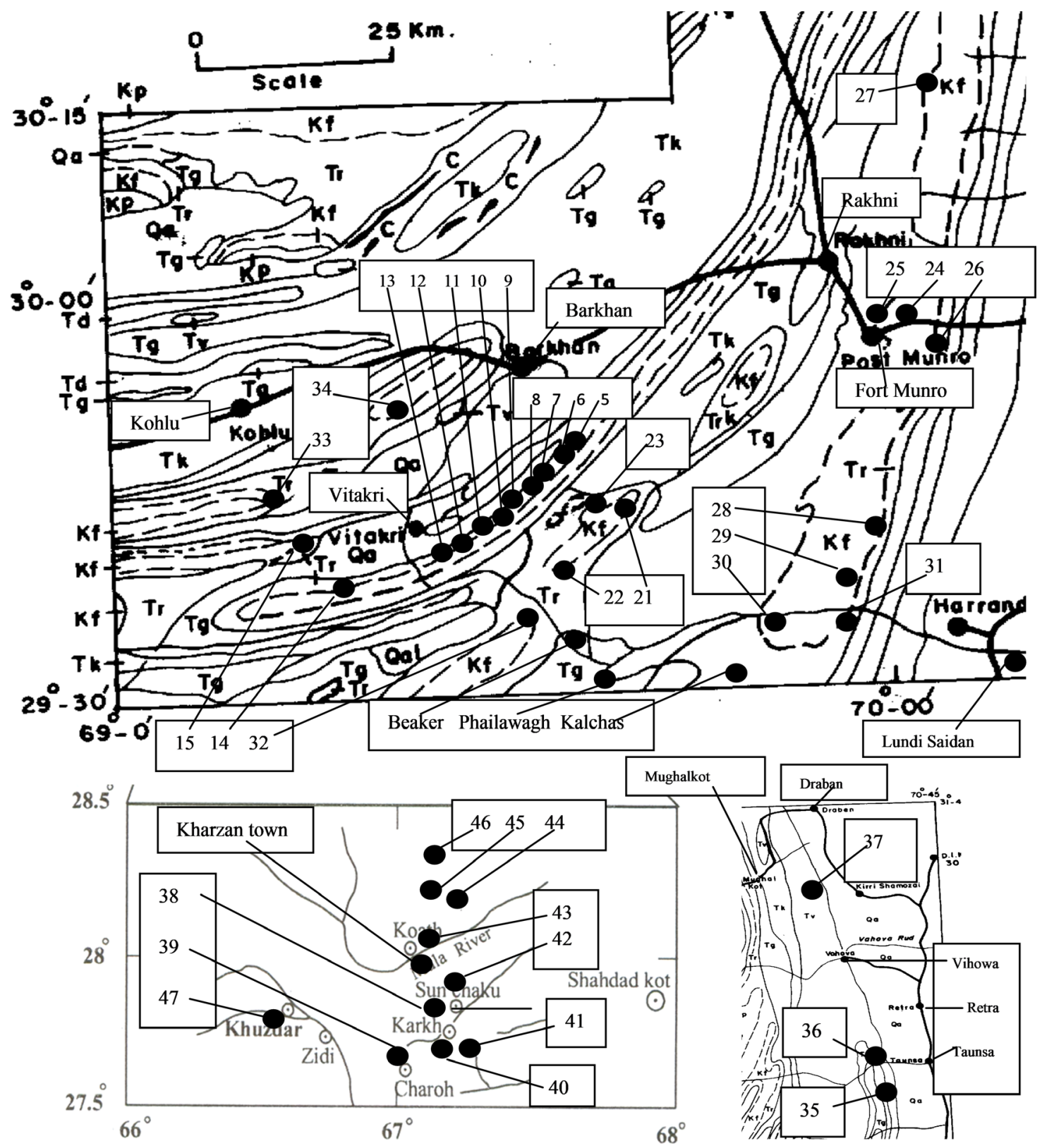

Figure 1. Black circles represent fossil localities found in Barkhan (1-21, 23, 33, 34), Kohlu (23, 32), Dera Bugti (22, 32), Musa Khel (37), and Khuzdar (38-47) districts of Balochistan, and Dera Ghazi Khan (24-27, 35-36)) and Rajan Pur (28-31) districts of South Punjab, Pakistan. Upper, Geological Map of Koh Sulaiman (modified after [12]) includes localities Dagar-5; Goes Wanga Pass-6; Zubra (Basti Nala)-7; Darwaza-8; Grut-9; Rahi Wali-10; northeast Dolwahi-11; east northeast Dolwahi-12; east Dolwahi-13; Sadiqani-Chapar-14; Mari Bohri-15; Mat Khetran-21; Bhal Pikal-22; Kachar-Jhabar-23 (boarder of Barkhan and Kohlu); Top Girdu Fort Munro-24; Khar Fort Munro-25; Rakhi Gaj-26; Shadiani Koh Sulaiman-27; Chitri-28; Dragal-29; Maarri-30; Kaha-Harrand-31; Siah Koh-32 (boarder of Kohlu and Dera Bugti); Kachi Bohri-Mawand-33; Jandran-34. (Vitakri dome localities 1-4, 16-20 was shown in Figure 4 of [1] (there upper right map is mistyped as left right map and vice versa), and Figure 1 \& Figure 2 of [8]). Lower Right Map, Geological Map of eastern Koh Sulaiman (full map found in [12]), Mahoi-35; Gulki-36; Zamri-37. Lower Left Map, (modified after [7]), Sun Chaku-38; Charow-39; south Karkh-40; east Karkh (Pir Bari road)-41; southeast Kharzan (Kharzan-Karkh road)-42; north Kharzan-43; Kil-44; Chotok-45; Madan-Jhukur-46 and Khuzdar-47. Each fossil locality number is mentioned with relevant district name as above. The fossil locality numbers are represented in rectangles as above and also commonly just after the fossil locality names in reports. Legend and Symbols; Qa-Alluvium; Tv-Vihowa Group; Tk, Kahan Group; Tg, Chamalang Group; Tr, Sangiali Group; Kf, Fort Munro Group; Kp, Parh Group; Js, Sulaiman Group. Contact-thin line; Cretaceous/Paleogene Boundary-dashed line; Rud/Nala/Stream-irregular line; Road-thick line. 

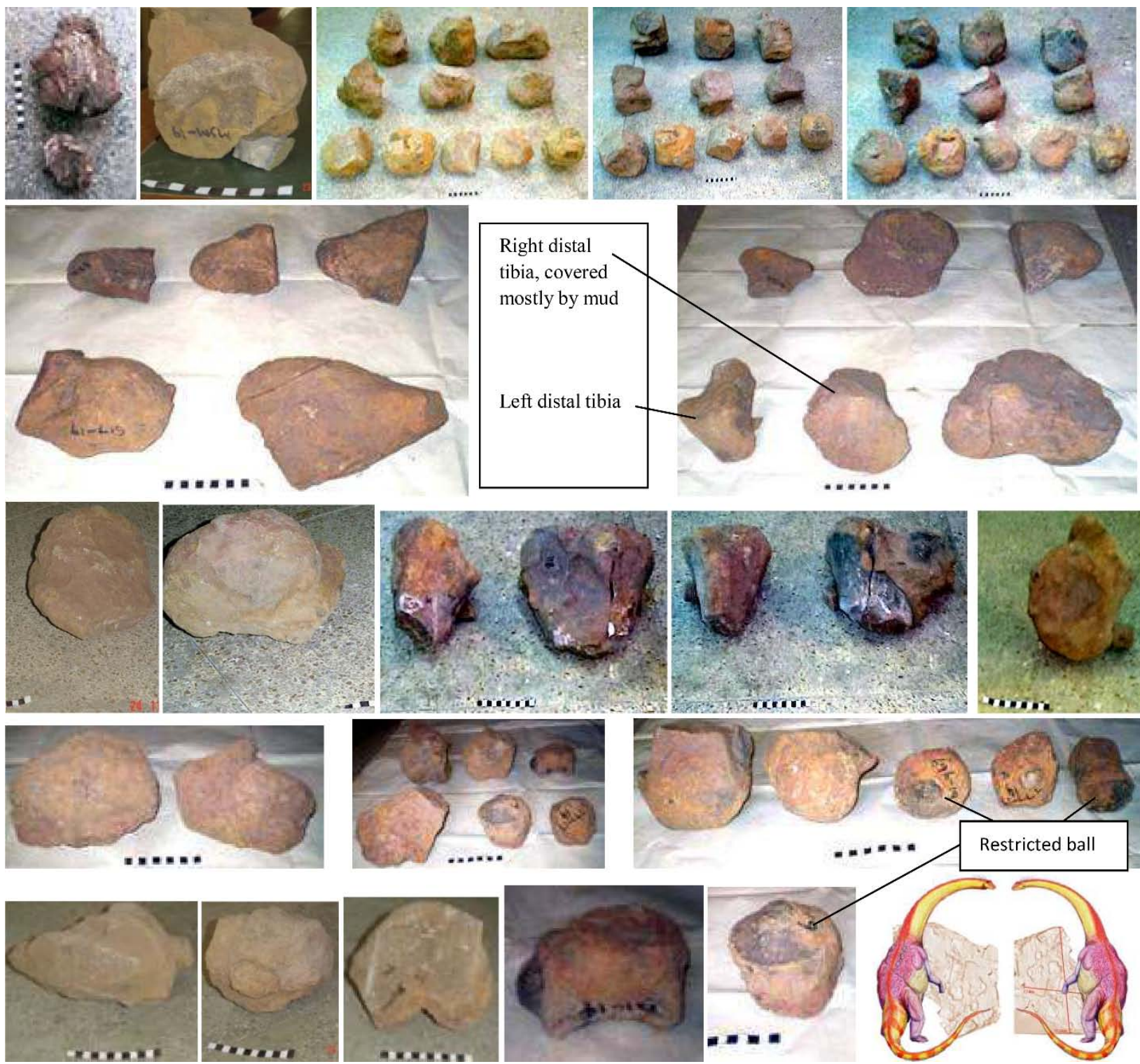

Figure 2. Gspsaurus pakistani holotype (rows 1 - 5 except the last 2 photos of models) found from Alam 19 type locality (Figure 4 of [1]), Barkhan district, Balochistan Province, Pakistan. Maojandino alami holotype (rows $1-5$ except the $1^{\text {st }}$ photo/plate of row 1 and last 2 photos of row 5) found from Alam 19 type locality (Figure 4 of [1]), Barkhan district, Balochistan Province, Pakistan. Row 1, photo 1/plate 1/p1, skull 2 pieces GSP/GSP/MSM-79-19, GSP/MSM-80-19; p2, braincase GSP/ MSM-62-19 in anterior view; p3,4,5, subrow 1, cervical vertebrae GSP/MSM-107-19, GSP/MSM-108-19, GSP/GSP/MSM109-19; subrow 2, dorsal vertebrae GSP/MSM-110-19, GSP/MSM-111-19, GSP/MSM-112-19; subrow 3, caudal vertebrae GSP/MSM-113-19, GSP/MSM-114-19, GSP/MSM-115-19, GSP/MSM-116-19, GSP/MSM-117-19. Row 2, p1, subrow 1, cervical vertebrae GSP/MSM-437-19, GSP/MSM-220-19, GSP/MSM-502-19; subrow 2, dorsal vertebra GSP/MSM-617-19, partial ilia/sternal GSP/MSM-216-19; p2, subrow 1, proximal radius GSP/MSM-215-19; proximal left tibia GSP/MSM-119-19; proximal left femur GSP/MSM-213-19; subrow 2, distal left tibia GSP/MSM-569-19; distal right tibia GSP/MSM-710-19; distal left femur GSP/MSM-118-19. Row 3, p1, 2, proximal left tibia GSP/MSM-119-19; p3, 4, distal right tibia GSP/MSM-710-19 anddistal left femur GSP/MSM-118-19 in 2 views; p5, transversely elongated oval shaped right distal tibia GSP/MSM-710-19 in ventral view; Row 4, p1, left and right partial distal scapulaGSP/MSM-1100-19, GSP/MSM-217-19; p 2, subrow 1, caudal vertebrae GSP/MSM-219-19, GSP/MSM-218-19 and GSP/MSM-221-19; Row 5, p1, 2, 3, vertebral process/neural arch GSP/MSM146-19 in 3 views; p4, 5, restricted posterior articular ball GSP/MSM-221-19 and GSP/MSM-696-19; p6, 7, Gspsaurus models managed by British Journalist Nicholas Allen and prepared by Russian Paleoartist Dr. Dmitry Bogdanov. Scale, Each black or white digit is 1 centimeter $(\mathrm{cm})$. 
Maojandino alami new genus and new species (Figure 2).

Holotype: Partial braincase GSP/MSM-62-19; cervical vertebrae GSP/MSM107-19 to GSP/MSM-109-19, GSP/MSM-437-19, GSP/MSM-220-19 and GSP/MSM-502-19; dorsal vertebrae GSP/MSM-110-19 to GSP/MSM-112-19 and GSP/MSM-617-19; caudal vertebrae GSP/MSM-113-19 to GSP/MSM-117-19, GSP/MSM-218-19, GSP/MSM-219-19, GSP/MSM-221-19, GSP/MSM-696-19 and GSP/MSM-777-19; left and right partial distal scapula GSP/MSM-1100-19, GSP/MSM-217-19; proximal radius GSP/MSM-215-19; partial ilia GSP/MSM216-19; proximal left femur GSP/MSM-213-19 and distal left femur GSP/MSM118-19; proximal left tibia GSP/MSM-119-19; distal left tibia GSP/MSM-569-19; distal right tibia GSP/MSM-710-19; and vertebral process GSP/MSM-146-19 (Figure 2) (Figure 6 of [1]) and many specimens partially covered by brown

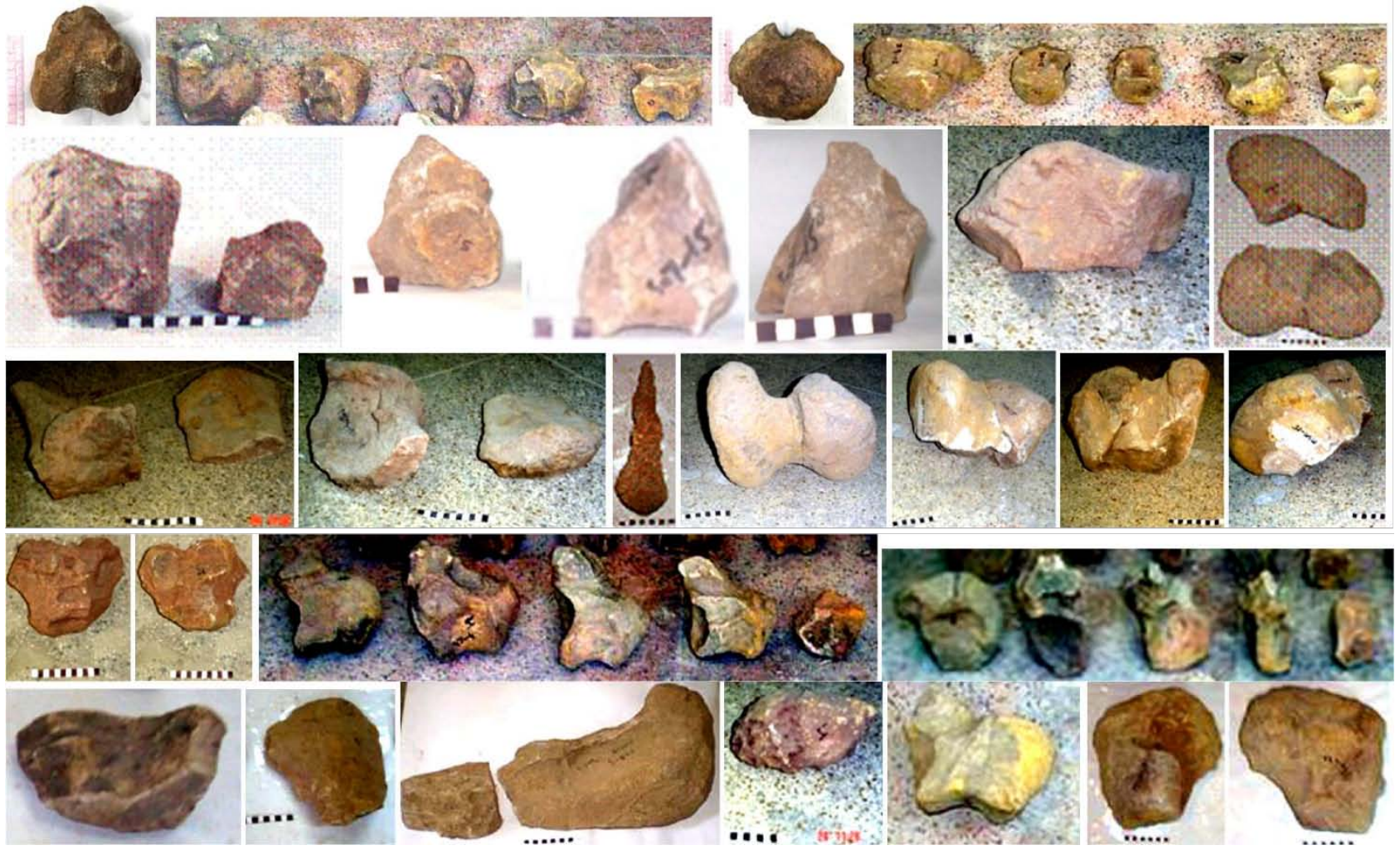

Figure 3. Gspsaurus pakistani referred assemblages from Mari Bohri 15 (Figure 4 of [1]) (rows 1-3), south Kinwa 4 (Figure 4 of [1]) (row 4 and first 4 photos of row 5), Darwaza 8 (Figure 1) $\left(5^{\text {th }}\right.$ photo of row 5) and Rahi Wali 10 (Figure 1$)\left(6^{\text {th }}\right.$ and $7^{\text {th }}$ photos of row 5), Barkhan district, Balochistan [1] [2]. Marisaurus jeffi holotypic skeleton (rows 1-3) from Mari Bohri 15 (Figure 4 of [1]). Row 1, biconvex first caudal vertebra GSP/MSM-7-15; and five caudal vertebrae GSP/MSM-29-15, GSP/MSM-30-15, GSP/MSM-31-15, GSP/MSM-32-15, GSP/MSM-33-15 in 2 views. Row 2, caudal vertebrae GSP/MSM-815-15, MSM-808-15; special trirays distalmost caudal centrum GSP/MSM-507-15 in anterior, posterior and lateral views; distal right scapula GSP/MSM-163-15; proximal femur GSP/MSM-169-15 (upper) and distal femur GSP/MSM-70-15 (lower). Row 3, proximal pubis GSP/MSM-165-15 and distal pubis GSP/MSM-164-15 in 2 views; distal pubis GSP/MSM-164-15; distal femur GSP/MSM-70-15 in 4 views. Row 4, atlas-axis complex GSP/MSM-82-4 in 2 views; associated caudal vertebrae GSP/MSM-36-4, GSP/MSM-37-4, GSP/ MSM-38-4, GSP/MSM-39-4, and GSP/MSM-39(a)-4 in lateral and anterior views. Row 5, mid scapular blade with ridge GSP/ MSM-838-4; right mid and distal scapula GSP/MSM-198-4; proximal and mid femur GSP/MSM-208-4; osteoderm ellipsoidal plate GSP/MSM-85-4; caudal vertebra GSP/MSM-40-8; proximal humerus GSP/MSM-237-10 in 2 views. Scale each black or white digit is $1 \mathrm{~cm}$. For other scale pl. see [2]. For biconvex vertebra the scale is in $\mathrm{cm}$ and inches, total scale $15 \mathrm{~cm}$. 
muds stored in GSP museum. This assemblage was also shown in Figure 3 \& Figure 4 of [2]. The braincase was found associated with the postcranial skeleton. Further the matrix and size of braincase matches with postcranial assemblage of

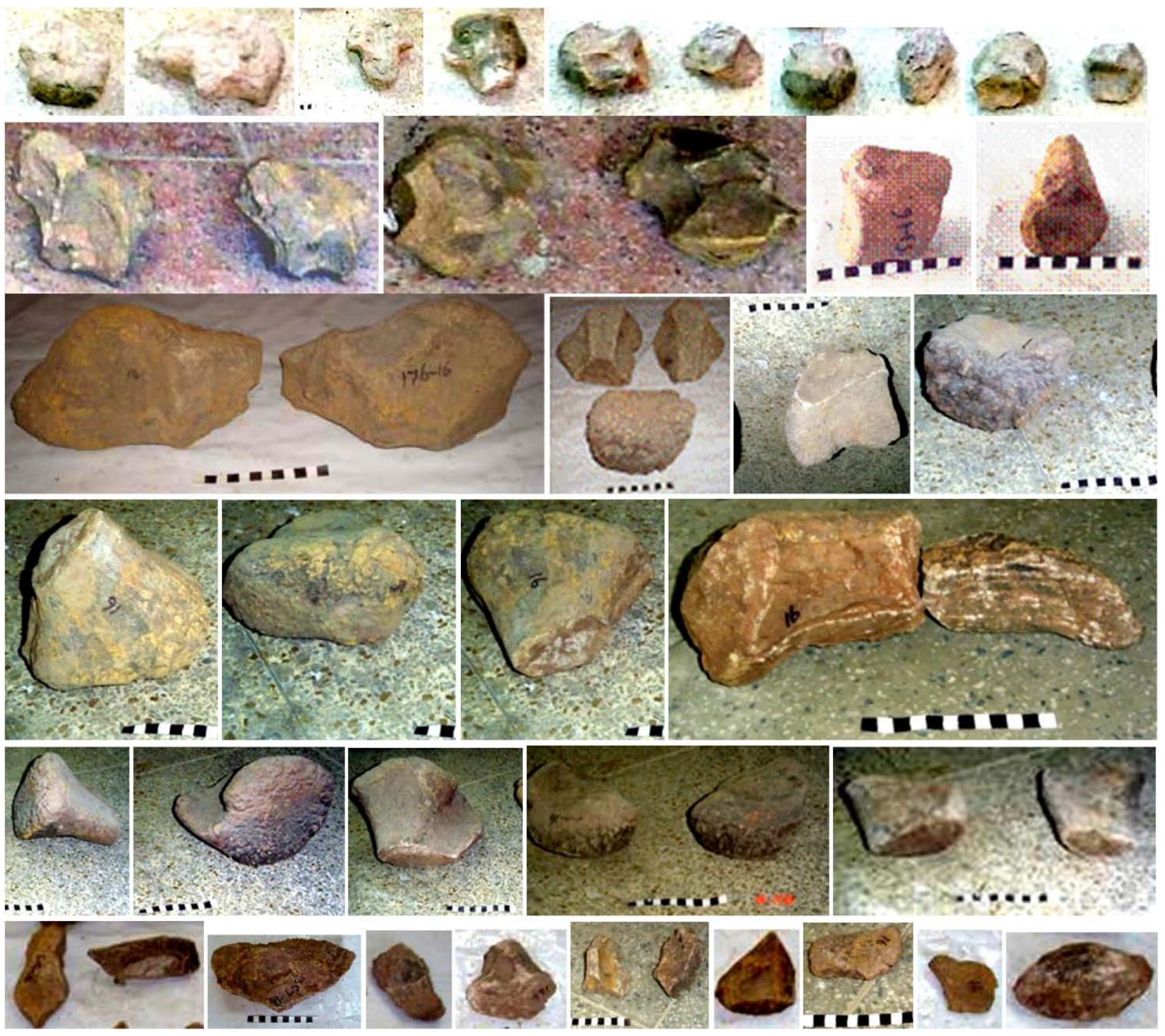

Figure 4. Gspsaurus pakistanireferred fossil assemblage from Top Kinwa 16 (Figure 4 of [1]). Row 1, a pair of coosified sacral vertebrae GSP/MSM-137-16 in 4 views; dorsal vertebrae GSP/MSM-131-16 and GSP/MSM-132-16 in 3 views. Row 2, caudal vertebrae GSP/MSM-34-16 and GSP/MSM-35-16 in lateral and ventral views; distal caudal vertebra GSP/MSM-153-16 in 2 views. Row 3, a pair of left and right distal scapulae GSP/MSM-250-16, GSP/MSM-176-16; a pair of left and right proximal ulna GSP/MSM-175-16 and GSP/MSM-240-16 (upper), distal ulna GSP/MSM-74-16 (lower); distal ulna GSP/MSM-74-16 in 2 views. Row 4, distal radius GSP/MSM-160-16 in 3 views; acetabulum in 2 pieces GSP/MSM-147-16 and GSP/MSM-148-16. Row 5, typical proximal right tibia biconvex lense shaped GSP/MSM-73-16 in 3 views; left and right proximal fibulae GSP/MSM-76-16 and GSP/MSM-77-16 in 2 views. Row 6, photo 1 (p1), convex part of sternal GSP/MSM-1014-16, sternal part GSP/MSM-604-16; p2, part of ilia GSP/MSM-557-16, p3, part of ilia or spine with glenoid or wound mark GSP/MSM-150-16, p4, vertebral process/distal rib/distal spine/metatarsal/metacarpalGSP/MSM-391-16; p5, distal cervical ribs GSP/MSM-328-16, GSP/MSM-329-16; p6, distal cervical rib GSP/MSM-767-16; p7, mosaic type osteoderm GSP/MSM-83-16; p8, mosaic type osteoderm GSP/MSM-1035-16; p9, osteoderm or platy oval ungual or sacral vertebrae GSP/MSM-776-16. Scale each black digit is $1 \mathrm{~cm}$. For other photo/plates pl. see [2]. 
Maojandino alami, and the features like decurved and much taller paraoccipital processes of braincase matches with titanosaur braincase along with other features. The assemblage found as surface finds in the same site, same formation, with fit size and no duplication show association of a single holotypic individual. Further some vertebrae show straight alignment and partially embedded in the clays of host Vitakri Formation. Fossils are housed in the museum of Geological Survey of Pakistan, Quetta.

Two assemblages were found in central Alam site, about 50m away from each other. These two assemblages were considered associated [1] [2] and assigned holotype of Gspsaurus pakistani (Figure 6 of [1]; Figures 1-4 of [2]). If these two assemblages may not be consider associated due to being $50 \mathrm{~m}$ away from each other, then the first assemblage snout and associated skull materials GSP/MSM79-19 and GSP/MSM-80-19 is the holotype of Gspsaurus pakistani as shown in Figure $1 \&$ Figure 2 of [2] and $1^{\text {st }}$ photo/plate of $1^{\text {st }}$ row of Figure 6 of [1], and the second assemblage is the holotype of Maojandino alami as shown above and also in Figure 3 \& Figure 4 of [2], and Figure 6 of [1] (all fossils except the $1^{\text {st }}$ photo/plate of $1^{\text {st }}$ row), there the prefix GSP/should be considered in specimen numbering like GSP/MSM-79-19 (instead of MSM-79-19), if already not mentioned.

Type locality, horizon and age: Holotype was discovered in Alam 19 or Alam central $19 \mathrm{c}$ (latitude $29^{\circ} 41^{\prime} 0.7^{\prime \prime} \mathrm{N}$; longitude $69^{\circ} 23^{\prime} 58^{\prime \prime} \mathrm{E}$ ) (Figure 4 of [1]) of Vitakri dome area, Barkhan district, Balochistan. Host horizon is the Vitakri Formation of Fort Munro Group [1] [4] [8] [16] [17]. Age is latest Maastrichtian [4] [12].

Etymology: Genus Maojan, honors late Shaheed Wadera Maojan Mari or commonly called Maozan Mari for his kind cooperation for the study in the area, dino, Greek for terrible lizard. Species M. alami is after nearby lands of Alam Khetran.

Diagnosis: Maojandino alami medium sized sauropod shares with Titanosauria as vertebrae lacking hyposphene-hypantrum articulations; procoelous caudals; and forward insertion of neural arches on caudals. It shares with Poripuchia on basis of procoelous distal caudals. It shares with Gspsauridae and Gspsaurinae on the basis of ratio of transverse dorsal width to the transverse ventral width is less than 1.25, and also stocky tibia. Maojandino alami diagnosed as thick, reverse w-shaped occipital condyle and decurved and much taller paraoccipital process; very broad cervicals; slightly broad and less long dorsals; slightly tall caudals with reduced ventral width but relatively less reduced than Balochisaurus malkani and Nicksaurus razashahi; transversely thick and anteroposteriorly slightly long lense shaped proximal tibia and transversely broad oval shaped distal tibia (whilePakisaurus balochistani and Sulaimanisaurus gingerichi have flat proximal tibia and anteroposteriorly broad distal tibia). Its updated diagnosis can be seen in [2].

Description and discussion: Maojandino alami was first reported and de- 
scribed in the conference extended abstract 2015 [14] and later on described in 2015 [15]. Its holotypic assemblage described in [18]. Its updated description can be seen in [2].

\subsubsection{Marisaurus jeffi Titanosaur from the Vitakri Formation of Pakistan Systematic paleontology}

Dinosauria; Saurischia; Sauropoda; Titanosauriformes; Titanosauria; Poripuchia [1]; Gspsauridae [1]; Gspsaurinae [1];

Marisaurus jeffi new genus and new species

(Figure 3 including following specimens); (Figure 6 of [2])

Holotype: Caudal vertebrae GSP/MSM-7-15, GSP/MSM-29-15 to GSP/MSM33-15, GSP/MSM-815-15, GSP/MSM-808-15 and GSP/MSM-507-15; distal right scapula GSP/MSM-163-15; proximal pubis GSP/MSM-165-15 and distal pubis GSP/MSM-164-15; proximal femur GSP/MSM-169-15 and distal femur GSP/ MSM-70-15 (Figure 3). It can also be seen in Figure 6 of [2]. This holotype was found as two assemblages on 2 sites. The first site includes first biconvex caudal vertebra, pubis and femur which were found very close to each other and scapula was found within $5 \mathrm{~m}$ diameter. The other site consists of caudal vertebrae in linear assemblage (trending northeast to southwest direction) as surface finds but away about $50 \mathrm{~m}$ toward southwest from first site. Both sites are found on peak of shale dominant ridges which are separated by erosion shallow gully. All these holotypic materials seem to be associated as one individual due to same time finding as surface finds in the same formation, same locality, fit size morphology. While a few referred vertebrae of Pakisaurus and Sulaimanisaurus possibly found with the holotypic vertebrae of Marisaurus. Fossils are housed in the museum of Geological Survey of Pakistan, Quetta.

Type locality, horizon and age: Holotype was found in an area designated as Mari Bohri locality 15 (latitude $29^{\circ} 42^{\prime} 08^{\prime \prime} \mathrm{N}$; longitude $69^{\circ} 15^{\prime} 08^{\prime \prime} \mathrm{E}$ ) (Figure 1), Barkhan district, Balochistan Province, Pakistan. Host horizon is Vitakri Formation of Fort Munro Group [1] [4] [8] [16] [17]. Age is latest Maastrichtian [4] [12].

Etymology: Genus Mari, honors the Mari tribe of the host area, saurus, Greek for reptile. Species $M$. jeffi honors the paleontologist Dr. Jeffery A. Wilson of University of Michigan who verified the thought of author (MSM) regarding identification of first dinosaur bones from Pakistan.

Diagnosis: Marisaurus jeffi share with Titanosauria as procoelous caudals, forward insertion of neural arches on caudals, and vertebrae lacking hyposphene-hypantrum articulations and neural spine seems to be single and not bifid. Marisaurus jeffi shares with Poripuchia on basis of procoelous distal and distalmost caudals. It shares with Gspsauridae and Gspsaurinae on the basis of ratio of transverse dorsal width to the transverse ventral width is less than 1.25 , and also stocky tibia. Marisaurus jeffi characterised as slight ventral reduction of caudals like Maojandino alami while Balochisaurus malkani and Nicksaurus razashahi have strong reduction of caudals, Pakisaurus balochistani, Sulaimanisaurus gingerichi and Khetranisaurus barkhani have mostly no ventral reduction 
of caudals, ball like biconvex first caudal while Balochisaurus malkani has broad first biconvex caudal; pubis iliac symphysial part is low and reduced, while the Isisaurus colberti has elevated iliac symphysial; close occurrence of low iliac symphysial and adjoining wide and thick glenoid (Figure 3).

Description: Marisaurus jeffi holotypic caudal vertebrae were first reported and described in conference 2004 [9] and later on described and figured (5 vertebrae) in 2006 [12]. Its holotypic first biconvex and other 5 vertebrae were figured in 2020 [2]. Its complete holotype was first figured as Figure 6 of [2]. Its updated description and comparisons can be seen in [2], by adding prefix GSP/ in specimen numbering.

\subsubsection{Sulaimanisaurus gingerichi Poripuchian Titanosaurs from Pakistan} Sulaimanisaurus gingerichi [1] was initially reported in conference 2004 [9] and 2006 [12], and formally figured (Figure 5 of [1]) and described in 2021 [1]. It has square shaped mid caudal vertebrae, transversely compressed flat proximal and distal tibia while Gspsaurus and Saraikimasoom have relatively more transversely expanded proximal and distal tibia, and radial condyle of humerus no expanded anteriorly [1].

\subsubsection{Khetranisaurus barkhani Titanosaur from Vitakri Formation of Pakistan}

Khetranisaurus barkhani [1] was initially reported in conference 2004 [9] and 2006 [12], and formally figured (Figure 5 of [1]) and described in 2021 [1]. Among Pakistani titanosaurs, it has unique feature like the ratio of mid transverse width of dorsal view to the ventral view of mid caudal is less than 1 . It represents the dorsal view is relatively less wide than ventral view which is more wide [1].

\subsubsection{Gspsaurus pakistani Poripuchian Titanosaurs from Pakistan}

Systematic paleontology

Dinosauria; Saurischia; Sauropoda; Titanosauriformes; Titanosauria; Poripuchia [1]; Gspsauridae [1]; Gspsaurinae [1]; Gspsaurus [1].

Gspsaurus pakistani [1] (Figure 2) (Figure 3) (Figure 4) (Figure 5)

Holotype: The cranial and postcranial fossils (Figure 2) were formally established as holotype [1] and also shown in Figure 6 of [1] and Figures 1-4 of [2].

Referred specimens: The assemblages referred from Mari Bohri 15 (Figure 3), south Kinwa 4, Top Kinwa 16, mid Bor 2, Rahi Wali 10and Darwaza 8 localities (Figure 1) (Figure 4 of [1]) of Pakistan and Chhota Simla skeleton from India [2]. The reasons of referring were clearly mentioned in [2]. Gspsaurusreferred skeleton of Mari Bohri 15 consists of vertebrae and appendicular elements (Figure 3). Gspsaurus pakistani referred materials from south Kinwa 4 (Figure 4 of [1]) consists of atlas-axis complex GSP/MSM-82-4; associated caudal vertebrae GSP/MSM-36-4, GSP/MSM-37-4, GSP/MSM-38-4, GSP/MSM-39-4, and GSP/MSM-39(a)-4; mid scapular blade with ridge GSP/MSM-838-4; right mid and distal scapula GSP/MSM-198-4; proximal and mid femur GSP/MSM-208-4; 

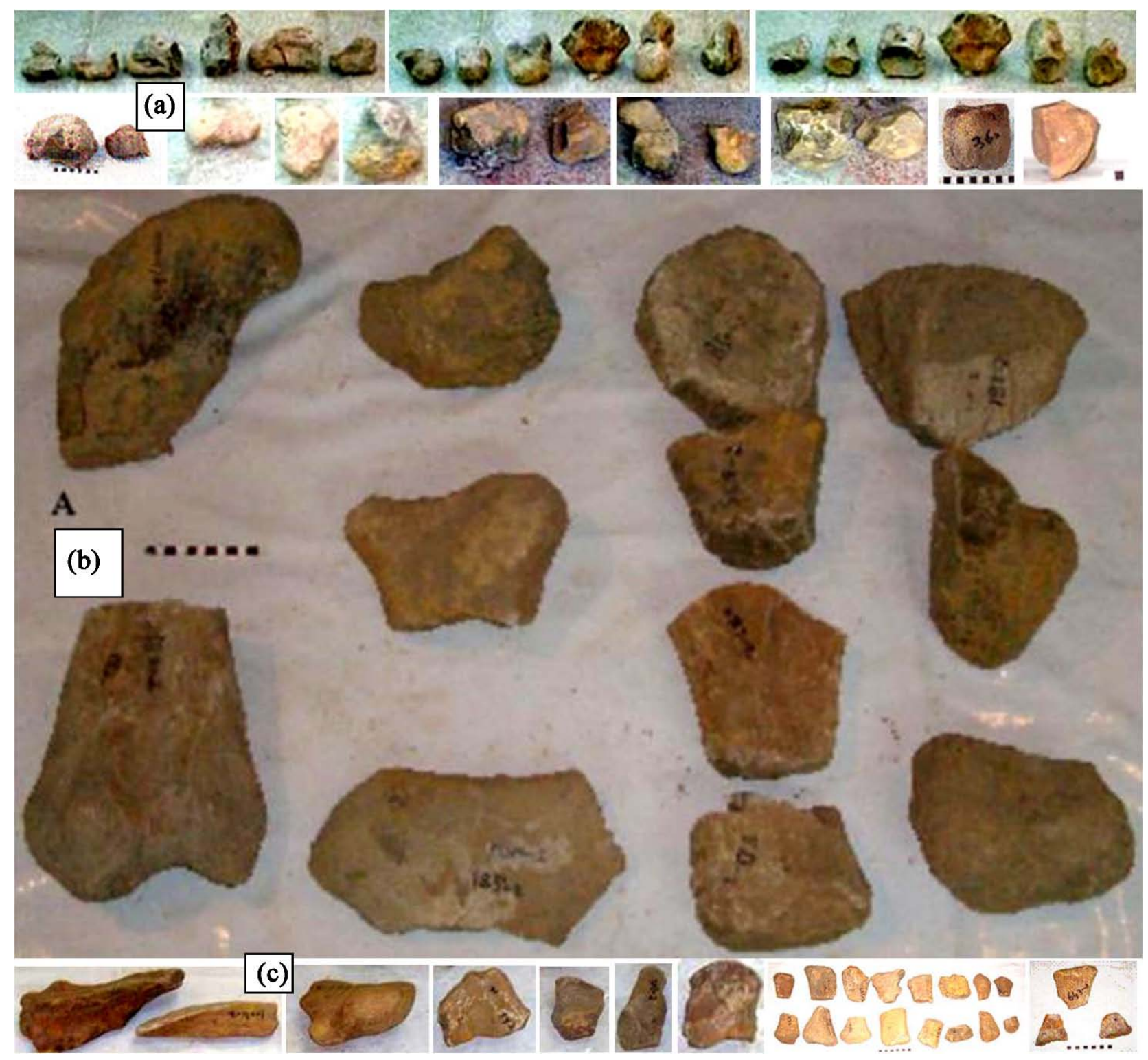

Figure 5. Saraikimasoom vitakri referred following assemblage (except tibial elements) from mid Bor locality 2 (Figure 4 of [1]) and Gspsaurus pakistani referred tibia (GSP/MSM-181-2 and GSP/MSM-850-2) possibly from east Bor site (about 100m toward east from mid Bor 2). (a) Row 1, cervicodorsal vertebra GSP/MSM-120-2 and dorsal vertebrae GSP/MSM-121-2, GSP/MSM-122-2, GSP/MSM-123-2, GSP/MSM-124-2, GSP/MSM-125-2 in 3 views. Row 2, p1, cervical vertebra GSP/MSM-359-2, dorsal vertebra GSP/MSM-441-2; p2,3,4, a pair of sacral vertebrae GSP/MSM-135-2 in 3 views; p5,6,7, caudal vertebrae GSP/MSM-41-2 and GSP/MSM-42-2 in lateral, posterior and ventral views; p8, caudal vertebra GSP/MSM-360-2; p9, trirays distal caudal centrum GSP/MSM-302-2. (b) column 1, a femur (proximal and distal femur GSP/MSM-178-2 and GSP/MSM-182-2); column 2, proximal ulna GSP/MSM-573-2, proximal ulna GSP/MSM-271-2, and proximal ischium GSP/MSM-184-2; column 3, proximal tibial shaft cross sectional part GSP/MSM-850-2; humerus mid-shaft cross section GSP/MSM-559-2; humerus part GSP/MSM-287-2; distal ulna GSP/MSM-852-2; column 4, proximal tibia GSP/MSM-181-2; partial proximal humerus/ilium GSP/MSM-363-2; distal humerus GSP/MSM-362-2. (c) p1, anterolateral part of sternal GSP/MSM-565-2 and sternal part GSP/MSM-1004-2; p2, prezygapophyses and postzygapophyses or coracoid GSP/MSM-560-2; p3, distal part of cervical rib GSP/MSM-187-2; p4, distal dorsal rib GSP/MSM-301-2; p5, neural spine GSP/MSM-792-2; p6, distal rib/neural spine GSP/MSM-784-2; p7, subrow 1, proximal metacarpals GSP/MSM-295-2,GSP/MSM-279-2, GSP/MSM-685-2, GSP/MSM-566-2, GSP/MSM-278-2, GSP/MSM-686-2, GSP/MSM-1029-2, GSP/MSM-688-2; subrow 2, distal metacarpals GSP/MSM-277-2, GSP/MSM-1028-2, GSP/MSM-285-2, GSP/MSM-370-2, GSP/MSM-684-2, GSP/MSM-687-2, GSP/MSM-361-2, GSP/MSM-683-2; p8, metatarsal GSP/MSM-643-2 (upper), and metatarsals GSP/MSM-1031-2 and GSP/MSM-1030-2 (lower). Scale each black digit is $1 \mathrm{~cm}$. For other scale pl. see [2]. 
and osteoderm ellipsoidal plate GSP/MSM-85-4 (Figure 3). Gspsaurus pakistanireferred caudal vertebra GSP/MSM-40-8 (Figure 3) found from Darwaza locality 8 (Figure 1) and proximal humerus GSP/MSM-237-10 (Figure 3) from Rahi Wali locality 10 (Figure 1) of northwestern limb of Dhaola Range trending northeast to southwest.

Gspsaurus pakistaniassemblage (Figure 4) from Top Kinwa locality 16 (Figure 4 of [1]) consists of a pair of coosified sacral vertebrae GSP/MSM-137-16; dorsal vertebrae GSP/MSM-131-16 and GSP/MSM-132-16; caudal vertebrae GSP/MSM-34-16 and GSP/MSM-35-16; distal caudal vertebra GSP/MSM-153-16 showing anteroposteriorly long and shallow neural spine on cylindrical centrum; a pair of left and right distal scapulae GSP/MSM-250-16, GSP/MSM-176-16; a pair of left and right proximal ulna GSP/MSM-175-16, GSP/MSM-240-16; distal ulna GSP/MSM-74-16; distal radius GSP/MSM-160-16; acetabulum in 2 pieces GSP/ MSM-147-16 and GSP/MSM-148-16; proximal typical right tibia with biconvex lense shaped proximal view GSP/MSM-73-16; left and right proximal fibulae GSP/MSM-76-16 and GSP/MSM-77-16; convex part of sternal GSP/MSM-1014-16; sternal part GSP/MSM-604-16; part of ilia GSP/MSM-557-16, part of ilia or spine with glenoid or wound mark GSP/MSM-150-16; vertebral process/distal rib/distal spine/metatarsal/metacarpalGSP/MSM-391-16; distal cervical ribs GSP/MSM-328-16, GSP/MSM-329-16 and GSP/MSM-767-16; mosaic type osteoderms GSP/MSM-83-16 and GSP/MSM-1035-16; platy oval ungual GSP/ MSM-776-16 (Figure 4).

Gspsaurus pakistani referred proximal tibial specimen GSP/MSM-181-2 and GSP/MSM-850-2 (Figure 5) may found from east Bor site [8]. These tibial specimens have differentiated white matrix, while Saraikimasoom vitakri referred assemblage from mid Bor site have light brown matrix. East Bor site is about $100 \mathrm{~m}$ eastward from mid Bor site 2 (Figure 4 of [1]). This tibia needs to confirm its assignment to either Gspsaurus pakistani or Saraikimasoom vitakri. The description of Gspsaurus will not be affected by this addition or deletion of tibia (and also mid Bor assemblage) because it has tibia from holotypic and Top Kinwa exemplar [2].

Locality, horizon and age: Holotype was discovered from Alam 19 locality (Figure 4 of [1]). The referred materials found from Mari Bohri 15, south Kinwa 4, Top Kinwa 16 and mid Bor 2 localities of Vitakri dome, Rahi Wali 10 and Darwaza 8 localities of Dhaola Range (Figure 4 of [1]) (Figure 1), Barkhan district, Balochistan. All these localities are found in terrestrial Vitakri Formation (in Figure 3 of [1]) of Fort Munro Group [1] [4] [8] [16] [17]. It is distributed in eastern Sulaiman (commonly called Koh Sulaiman) [1] [17] and also in the core of Laki anticline of eastern Kirthar basin [1]. Its age is the latest Maastrichtian [4] [12].

Diagnosis: The updated diagnosis and comparisons can be seen in [1] [2].

Description: Gspsaurus pakistani first appeared in conference 2014 [13] and later on in 2015 [15]. The updated detailed description found in 2020 [2], there the prefix GSP/should be considered in specimen numbering like GSP/MSM- 
79-19 (instead of MSM-79-19), if already not mentioned. It was formally described in 2021 [1].

\subsubsection{Saraikimasoom vitakri Poripuchian Titanosaurs from Pakistan} Systematic paleontology

Dinosauria; Saurischia; Sauropoda; Titanosauriformes; Titanosauria; Poripuchia [1]; Gspsauridae [1]; Saraikimasoominae [1]; Saraikimasoom [1].

Saraikimasoom vitakri [1] (Figure 5) (Figure 6) (Figure 7) (Figure 8)

Holotype: Snout GSP/MSM-142-4 (Figure 6) (Figure 5 of [1]) (Figure $1 \&$ Figure 2 of [3].

Referred specimens: Teeth size, shape and contact behavior of holotypic snout of Saraikimasoom resemble with the articulated teeth of north Kinwa skeleton. Consequently overlapping of typical vertebral and limb elements especially ventrally reduced caudals and relatively transversely more broader tibia of north Kinwa skeleton matches with assemblages/skeletons of Mari Bohri 15, mid Sangiali 1, south Zubra 7, Grut 9 and Top Kinwa 16 localities. Saraikimasoom referred partial skeleton from north Kinwa consists of cranial and postcranial elements (Figure 6). Saraikimasoom referred assemblage (Figure 7) found from southern sites of Mari Bohri. Saraikimasoom referred fossils from mid Kinwa $4 \mathrm{~m}$ include caudal vertebrae GSP/MSM-50-4, GSP/MSM-51-4, GSP/MSM512-4, GSP/MSM-514-4, GSP/MSM-811-4 GSP/MSM-515-4, GSP/MSM-808-4, GSP/MSM-1021-4m (north), GSP/MSM-1018-4m (north), GSP/MSM-1019-4m (north), GSP/MSM-1016-4m, GSP/MSM-1017-4m-south (Figure 6).

Fossil assemblage (Figure 5) from mid Bor 2 show affinity to Saraikimasoom due to ventral reduction of length and width of midcaudal and fit size matching. The mid Bor 2 site yielded cervicodorsal vertebra GSP/MSM-120-2; dorsal vertebrae GSP/MSM-121-2 to GSP/MSM-125-2; cervical vertebra GSP/MSM-359-2; dorsal vertebra GSP/MSM-441-2; a pair of sacral vertebrae GSP/MSM-135-2; caudal vertebrae GSP/MSM-41-2 and GSP/MSM-42-2; caudal vertebra GSP/ MSM-360-2; trirays distal caudal centrum GSP/MSM-302-2; distal part of cervical rib GSP/MSM-187-2; distal rib GSP/MSM-301-2; neural spine GSP/ MSM-792-2; distal rib/neural spine GSP/MSM-784-2; part of sternal GSP/ MSM-565-2 and sternal part GSP/MSM-1004-2; coracoid GSP/MSM-560-2; proximal ulna/distal scapula GSP/MSM-573-2; proximal humerus GSP/MSM363-2; mid shaft cross section GSP/MSM-559-2; distal humerus GSP/MSM-3622; humerus parts GSP/MSM-287-2; proximal ulna GSP/MSM-271-2; distal ulna GSP/MSM-852-2; proximal metacarpals GSP/MSM-295-2, GSP/MSM-279-2, GSP/MSM-685-2, GSP/MSM-566-2, GSP/MSM-278-2, GSP/MSM-686-2, GSP/ MSM-1029-2, GSP/MSM-688-2; proximal ischium GSP/MSM-184-2; a femur (proximal and distal femur GSP/MSM-178-2 and GSP/MSM-182-2); distal metacarpals GSP/MSM-277-2, GSP/MSM-1028-2, GSP/MSM-285-2, GSP/MSM370-2, GSP/MSM-684-2, GSP/MSM-687-2, GSP/MSM-361-2, GSP/MSM-683-2; metatarsal GSP/MSM-643-2 and metatarsals GSP/MSM-1031-2 and GSP/MSM1030-2 (Figure 5). The description of Saraikimasoom will not be added more 
because most of these bones of mid Bor were also found in its exemplars from north Kinwa, mid Sangiali, south Mari Bohri [3]).

Saraikimasoom assemblage from mid Sangiali 1represents 3 monospecific animals. The first large individual consists of postcranial fossils from GSP/Sangiali-1101

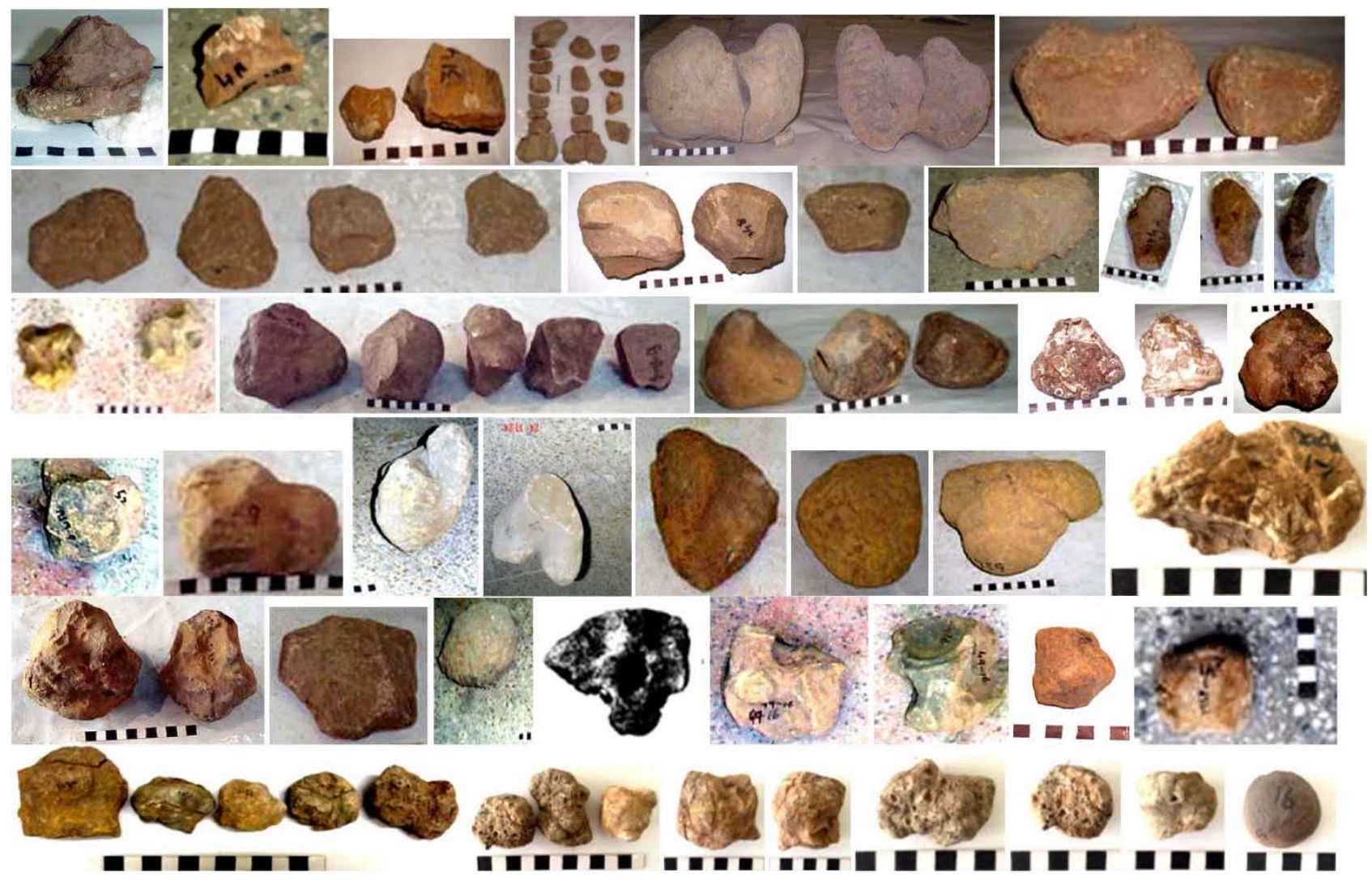

Figure 6. Saraikimasoom vitakri holotype (p1 of row 1) from South Kinwa 4, and referred fossils (rows 1-2 except p1 of row 1) from north Kinwa 4n and different localities (rows 3-6) [1] [3]. Nicksaurus razashahi holotypic skeleton (rows 1-2 except p1 of row 1) from north Kinwa 4n (Figure 4 of [1]).Row 1, p1, snout GSP/MSM-142-4; p2, six teeth in jaw ramus GSP/MSM-138-4n; p3, skull and teeth fragments in matrix GSP/MSM-315-4n and GSP/MSM-314-4n; p4, column 1, left femur GSP/MSM-190-4n; column 2, left and right distal tibiae GSP/MSM-346-4n, MSM-345-4n; femur sections GSP/MSM-378-4n, GSP/MSM-270-4n; distal femur GSP/MSM-192-4n; column 3, humerus parts GSP/MSM-380-4n, GSP/MSM-377-4n, GSP/MSM-379-4n, GSP/MSM-438-4n; p5, left and right distal femur GSP/MSM-190-4n, GSP/MSM-192-4n; p6, cervical vertebrae GSP/MSM-381-4n, GSP/MSM-382-4n. Row 2, p1, cervical vertebra GSP/MSM-381-4n, cervical/dorsal vertebra GSP/MSM-212-4n, cervical vertebra GSP/MSM-382-4n and GSP/MSM-383-4n; p2, caudal vertebrae GSP/MSM-347-4n and GSP/MSM-348-4n; p3, proximal radius GSP/MSM-344-4n; p4, proximal pubis GSP/MSM-1096-4n; p5,6,7, caudal chevron GSP/MSM-313-4n in 3 views. Row 3, Saraikimasoom vitakri referred fossils from south Kinwa 4 (p1-2) and mid Kinwa 4m (p3-7), p1, caudal vertebrae GSP/MSM-50-4, GSP/MSM-51-4; p2, caudal vertebrae GSP/MSM-512-4, GSP/MSM-514-4, GSP/MSM-811-4, GSP/MSM-515-4 and GSP/MSM-808-4; p3, caudal vertebrae GSP/MSM-1021-4m (north), GSP/MSM-1018-4m (north) and GSP/MSM-1019-4m (north); p4,5, broad caudal vertebra GSP/MSM-1016-4m in 2 views; p6, midcaudal vertebra GSP/MSM-1017-4m (south). Row 4, Saraikimasoom vitakri referred fossils from Grut 9 (p1-7) and Dada Pahi 17 (p8), p1, 2, caudal vertebra GSP/MSM-52-9, GSP/MSM-793-9; p3 4, typical distal tibia GSP/MSM-75-9 in 2 views; p5, right astragalus GSP/MSM-752-9 (transverse length $15 \mathrm{~cm}$, anteroposterior width $10 \mathrm{~cm}$ ); p6, distal ulna GSP/MSM-252-9; p7, proximal humerus mosaic of GSP/ MSM-694-9 and GSP/MSM-759-9); p8, osteoderm or cranial element GSP/MSM-1095-17. Row 5, Saraikimasoom vitakri referred fossils from Zubra 7 (p1-3) and east Top Kinwa 16 (p 4-7) and south Karkh (p8), p1, caudal vertebrae GSP/MSM-523-7 and GSP/MSM-524-7; p2, scapula GSP/MSM-746-7; p3, osteoderm GSP/MSM-84-7; p4, braincase (GSP/MSM-2-16; GSP-UM 7000); p5,6, caudal vertebra GSP/MSM-49-16 in 2 views; p7, metacarpalGSP/MSM-1036-16; p8, distal rib/neural spine GSP/MSM-5/02-Karkh. Row 6, coprolites or osteoderms GSP/MSM-1050, GSP/MSM-1051, GSP/MSM-1052, GSP/MSM-1053 and GSP/MSM-154 in different views and last photo GSP/MSM-155a found from Vitakri dome. Scale each black or white digit is $1 \mathrm{~cm}$. For other photo/plates scale see [3]. 


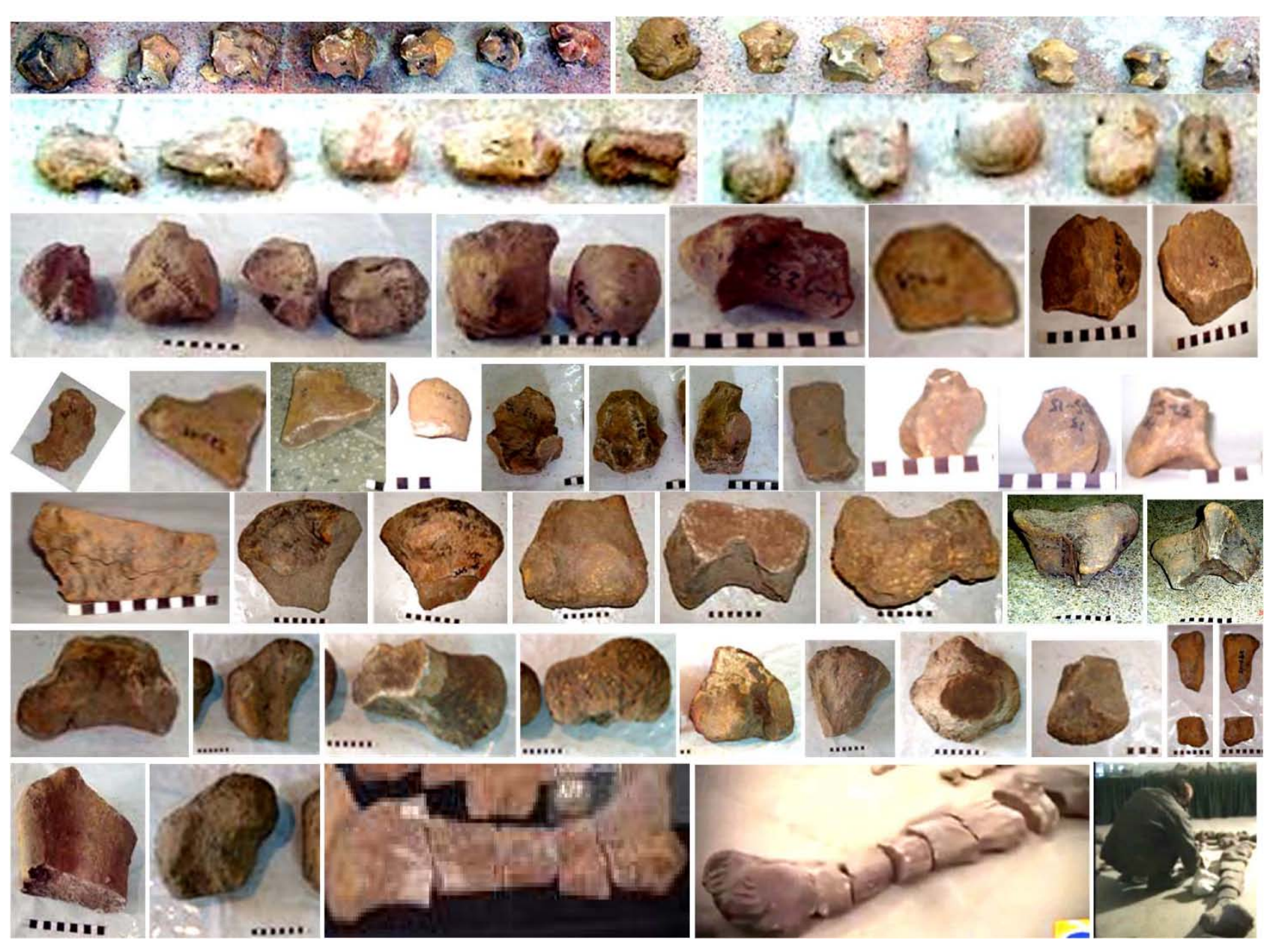

Figure 7. Saraikimasoom vitakri referred assemblage (rows 1-7) [3] found from Mari Bohri 15 locality (Figure 4 of [1]). Balochisaurus malkani holotypic fossils (rows 1-6) found from Mari Bohri 15 locality (Figure 4 of [1]), Barkhan district, Balochistan Province, Pakistan. Rows 1, caudal vertebrae GSP/MSM-43-15 (biconvex first caudal), GSP/MSM-44-15, GSP/MSM-44a-15, GSP/MSM-45-15, GSP/MSM-46-15, GSP/MSM-47-15, GSP/MSM-48-15 in lateral and ventral views. Row 2, five presacral vertebrae GSP/MSM-126-15, GSP/MSM-127-15, GSP/MSM-128-15, GSP/MSM-129-15, GSP/MSM-130-15 in lateral and anterior views. Row 3,presacral vertebrae GSP/MSM-824-15, GSP/MSM-823-15, GSP/MSM-822-15, GSP/MSM-818-15; caudal vertebrae GSP/MSM-260-15, GSP/MSM-505-15; caudal vertebra GSP/MSM-834-15 with prominent articular ring; proximal fibula/rib/arch GSP/MSM-672-15; cervical rib GSP/MSM-881-15 in 2 views. Row 4, posteriorly inclined neural spine of caudal GSP/MSM-324-15; proximal rib of dorsal vertebra GSP/MSM-322-15 in 2 views; neural spine GSP/MSM-1056-15; neural spine with post zygapophyses and prespinal laminae of dorsal vertebra GSP/MSM-323-15 in 3 views; mid rib of dorsal vertebra GSP/MSM-531-15; distalmost caudal centrum GSP/MSM-325-15 in anterior, posterior and lateral views. Row 5, left anterior sternal GSP/MSM-675-15; left proximal humerus GSP/MSM-245-15 in anterior and posterior views; and typical distal humerus GSP/MSM-174-15 in anterior, dorsal and ventral views; left proximal ulna GSP/MSM-78-15 in posterior and ventral views. Row 6, left acetabulum GSP/MSM-166-15 in ventral view; left proximal femur GSP/MSN-168-15 in posterior, ventral and dorsal views; distal left femur GSP/MSM-173-15 in posterior view; typical proximal left tibia in lateral and ventral views GSP/MSM-246-15; distal tibia/ulna? GSP/GSP/MSM-227-15; proximal metacarpal GSP/MSM-297-15 (upper) and distal metacarpal GSP/MSM-750-15 (lower) in 2 views. Row 7, proximal right femora GSP/MSM-749-15 and GSP/MSM-167-15; last 3 photos including femur and miscellaneous fossils in GSP museum, Quetta. Scale, each black/white digit is $1 \mathrm{~cm}$. For other photos scale pl. see [3].

to GSP/Sangiali-1122 and GSP/MSM-1-1; the $2^{\text {nd }}$ and $3^{\text {rd }}$ animals consist of vertebra GSP/Sangiali-1123; proximal right humeri GSP/Sangiali-1124 and GSP/ Sangiali-1125, along with their small sized bones/pieces of bones from GSP/ Sangiali-1126 to GSP/Sangiali-1174 (Figure 8). Saraikimasoom vitakri South 
Zubra 7 exemplar consists of mid caudal vertebrae GSP/MSM-523-7 and GSP/ MSM-524-7; right mid scapula GSP/MSM-746-7; and osteoderms large oval ellipsoidal plate GSP/MSM-84-7 (Figure 6). Saraikimasoom vitakri Grut 9 Gambrak

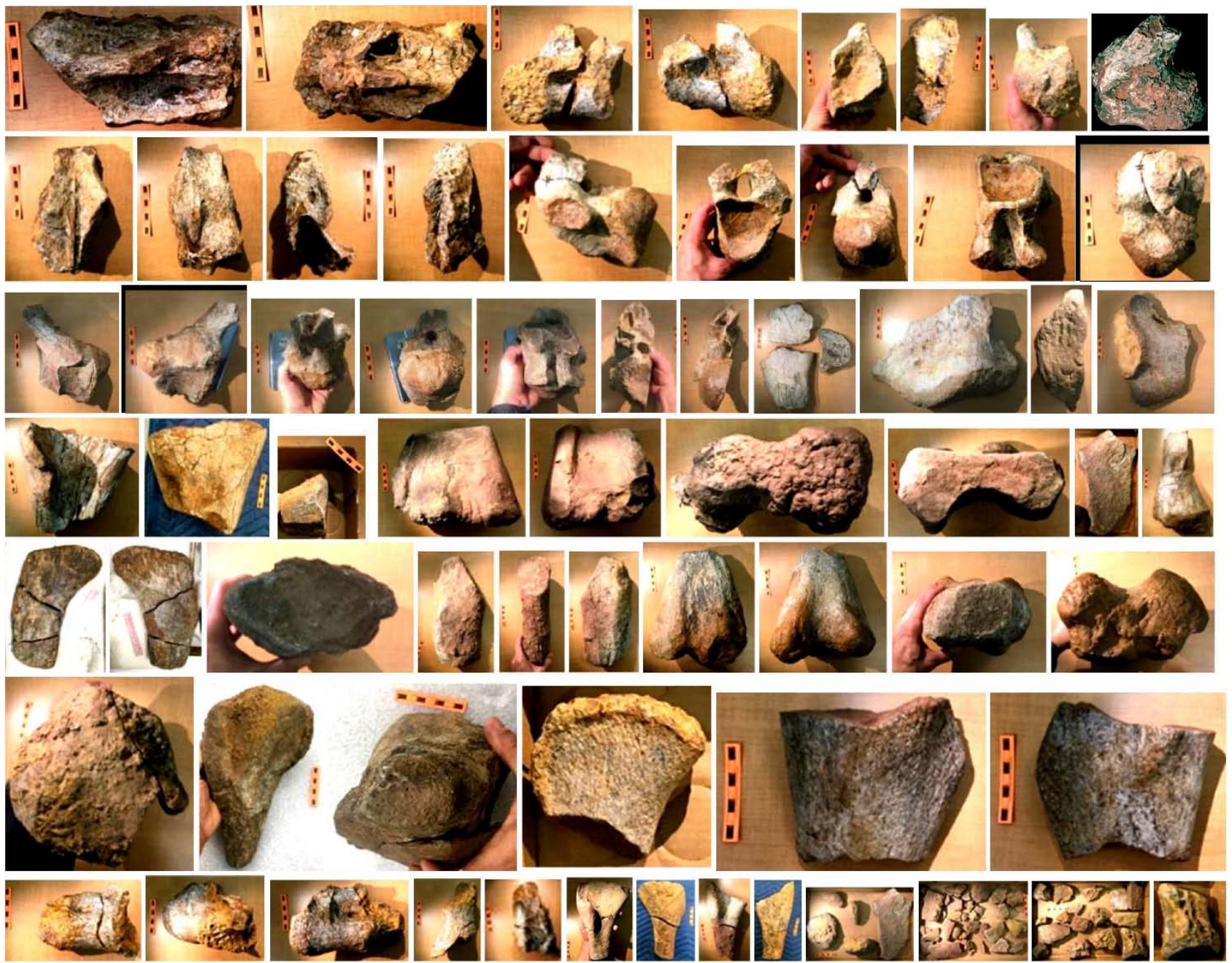

Figure 8. Saraikimasoom vitakri referred fossils from mid Sangiali 1 (Figure 4 of [1]) (rows 1-7 except GSP/Sangiali-1175). Row 1, Cervical vertebra GSP/Sangiali-1101 in 2 views; cervicodorsal vertebra GSP/Sangiali-1102 in 5 views; dorsal vertebra GSP/Sangiali-1103. Row 2, dorsal vertebra neural arch GSP/Sangiali-1104 in 4 views; caudal vertebra GSP/Sangiali-1105 in 5 views. Row 3, caudal vertebra GSP/Sangiali-1106 in 5 views; caudal vertebra GSP/Sangiali-1107 in 2 views; proximal left scapula GSP/Sangiali-1108 (top left image), proximal left scapula GSP/Sangiali-1109 (top right image), and left mid scapula GSP/Sangiali-1110 (lower image); distal left scapula GSP/Sangiali-1111 in 2 views; left Coracoid GSP/Sangiali-1112. Row 4, proximal right humerus GSP/Sangiali-1113 in 2 views; right humerus cross section GSP/Sangiali-1114; distal right humerus GSP/Sangiali-1115 in 4 views; partial proximal left pubis GSP/Sangiali-1116; distal left pubis GSP/Sangiali-1117. Row 5, proximal left femur GSP/Sangiali-1118 in posterior and anterior views; right proximal and mid femur GSP/Sangiali-1119 in 4 views; left distal femur GSP/MSM-1-1 (first time found dinosaur bone from Pakistan which started the discovery) in 4 views. Row 6, left typical proximal tibia GSP/Sangiali-1120 in 3 views. Proximal left fibula GSP/Sangiali-1121; mid left fibula GSP/Sangiali-1122 in 2 views with clear lateral trochanter. Row 7, p1-5, cervicodorsal vertebra GSP/Sangiali-1123 in 5 views; p6-7, proximal right humerus GSP/Sangiali-1124 in 2 views; p8-9, proximal right humerus GSP/Sangiali-1125 in 2 views; p10-12, miscellaneous fossils GSP/Sangiali-1126 to GSP/Sangiali-1175; p13, Vitakridrinda sulaimani theropod vertebra GSP/Sangiali-1175. Assemblage shows $1^{\text {st }}$ relatively large animal (rows 1-6), $2^{\text {nd }}$ and $3^{\text {rd }}$ monospecific animals (p1-9 of row 7) and their bones/pieces of bones (p10-12 of row 7 except GSP/Sangiali-1175). Scale each black digit is $1 \mathrm{~cm}$ (total scale $7 \mathrm{~cm}$ ), while in proximal femur the total scale is 6 inches or $15 \mathrm{~cm}$. 
exemplar consists of caudal vertebra GSP/MSM-52-9, GSP/MSM-793-9; stocky distal tibia GSP/MSM-75-9; right astragalus GSP/MSM-752-9 (transverse length $15 \mathrm{~cm}$, anteroposterior width $10 \mathrm{~cm}$ ); distal ulna GSP/MSM-252-9; proximal humerus with prominent head (mosaic of samples GSP/MSM-694-9 and GSP/MSM759-9) (Figure 6). Saraikimasoom vitakrireferred fossils ofeastern Top Kinwa includes braincase (GSP/MSM-2-16; GSP-UM 7000); caudal vertebra GSP/ MSM-49-16; and metacarpalGSP/MSM-1036-16 (Figure 6). Saraikimasoom vitakriDada Pahi 17 referred subrectangle or suboval shaped mosaic type osteoderms or may be cranial element GSP/MSM-1095-17 (Figure 6).

The Vitakri dome area of Barkhan district, Balochistan yielded five vesicular/ spongy coprolite fossils GSP/MSM-1050, GSP/MSM-1051, GSP/MSM-1052, GSP/MSM-1053 and GSP/MSM-154 (Figure 6). A fragmentary bone from Karkh 40 yielded distal rib/dorsal neural spine GSP/MSM-5/02-Karkh (Figure 6).

Locality, horizon and age: Holotype was discovered from south Kinwa 4 (Figure 4 of [1]). Referred materials found from north Kinwa 4n, Mari Bohri 15, mid Sangiali1, south Kinwa 4, mid Kinwa 4m, Top Kinwa 16, Dada Pahi 17 and mid Bor 2 localities of Vitakri dome area (Figure 4 of [1]), south Zubra 7 (Figure 1) and Grut 9Gambrak localities of Dhaola Range (Figure 1) of Sulaiman basin, under Barkhan district, Balochistan, Pakistan. Karkh locality $27^{\circ} 42^{\prime} 13^{\prime \prime N}$; $67^{\circ} 09^{\prime} 8 " \mathrm{E}$ ) (Figure 1) located in Kirthar basin, Khuzdar, Balochistan. Host horizon is Vitakri Formation of Fort Munro Group [1] [4] [8] [16] [17]. Age is latest Maastrichtian [4] [12].

Diagnosis: The updated diagnosis and comparisons can be seen in [1] [3].

Description: Saraikimasoom vitakri first appeared in conference 2014 [13] and later described in 2015 [15]. The updated detailed description found in 2020 [3], there theprefix GSP/may be added in specimen numbering like GSP/MSM7-15 (instead of MSM-7-15), if already not mentioned. It was formally described in 2021 [1].

\subsubsection{Pakisaurus balochistani Poripuchian Titanosaurs from Pakistan \\ Systematic paleontology}

Dinosauria; Saurischia; Sauropoda; Titanosauriformes; Titanosauria; Poripuchia [1]; Pakisauridae [1]; Pakisaurus [1]

Pakisaurus balochistani [1] (Figure 9)

Holotype: The vertebral, appendicular and limb elements were established as holotype [1] as shown in Figure 7 of [1] and Figures 1-3 of [4]. These holotypic materials belong to adult individual. All fossil remains were found disarticulated but associated in same site. Duplicate is proximal humerus which exhibits the same morphological characters. This evidences the presence of a monospecific assemblage.

Referred specimens: Pakisaurus balochistani associated skeleton from lower Bor 2 consists of partial dentary ramus with articulated teeth GSP/MSM-143-2; partial flattened proximal tibia GSP/MSM-72-2 and distal tibia GSP/MSM186-2; portion of proximal femur GSP/MSM-293-2 (may be adjusted with 


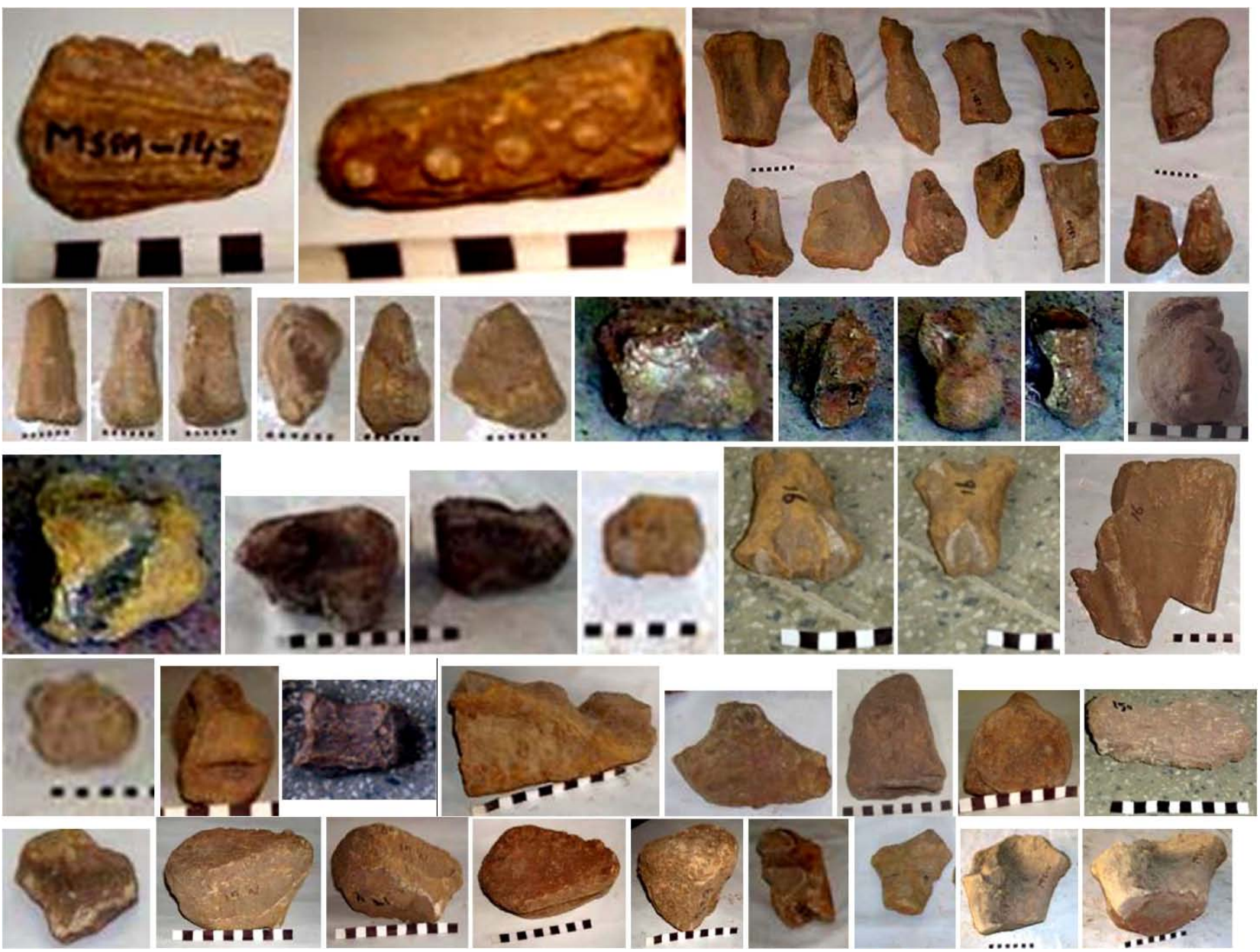

Figure 9. Pakisaurus balochistani lower Bor exemplar skeleton (rows 1-2) from lower Bor 2 locality (Figure 4 of [1]), and referred fossils (rows 3-5) from different localities. Row 1, p1,2, dentary ramus with articulated teeth GSP/MSM-143-2 in 2 views; p3, column 1, a partial right tibia including proximal slender tibia GSP/MSM-72-2, distal tibia GSP/MSM-186-2; column 2, portion of proximal femur GSP/MSM-293-2 (may be adjusted with proximal and mid femur GSP/MSM-294-2), distal humerus GSP/ MSM-180-2; column 3, proximal and mid femur GSP/MSM-294-2, part of distal femur GSP/MSM-266-2; column 4, mid humerus GSP/MSM-289-2, humerus part GSP/MSM-498-2; column 5, proximal partial humerus GSP/MSM-288-2 (proximal most and lateral part eroded), mid humerus GSP/MSM-290-2, mid tibia GSP/MSM-286-2; p4, proximal and mid femur (upper) GSP/ MSM-69-2, with distal condyles GSP/MSM-272-2 and GSP/MSM-265-2 (lower). Row 2, p1-3, distal fibula GSP/MSM-183-2 in 3 views; p4-6, part of distal femur ? GSP/MSM-233-2 in 3 views; p7-10, caudal vertebra GSP/MSM-16-2 in 4 views; p11, caudal vertebra GSP/MSM-793-2. Row 3, Pakisaurus balochistani fossils from Top Kinwa 16 (Figure 4 of [1]), caudal vertebrae GSP/ MSM-17-16, GSP/MSM-510-16 and GSP/MSM-154-16; prezygapophyses GSP/MSM-327-16; caudal chevron GSP/MSM-330-16 in 2 views; proximal ulna GSP/MSM-1032-16. Row 4, Pakisaurus balochistani fossils from Shalghara 3 (Figure 4 of [1]), fractured distal caudal vertebra GSP/MSM-523-3; distal caudal vertebra with horizontal groove on posterior cone GSP/MSM-151-3 in posterior and lateral views; proximal pubis with glenoid and fenestra GSP/MSM-366-3; ulna GSP/MSM-748-3; ungual GSP/MSM152-3 in 2 views; and spongy thick armour spine GSP/MSM-150-3. Row 5, Pakisaurus balochistani fossils from north Alam 19n (Figure 4 of [1]), proximal pubis GSP/MSM-403-19n; proximal radius GSP/MSM-756-19n in 3 views; distal ulna GSP/MSM628-19n and caudal vertebra GSP/MSM-758-19n. Pakisaurus balochistani proximal rib GSP/MSM-321-13 from East Dolwahi (Figure 1); proximal right humerus GSP/MSM-195-4 in 2 views found from south Kinwa 4 (Figure 4 of [1]). Scale each black digit is $1 \mathrm{~cm}$, for others see [4].

proximal and mid femur GSP/MSM-294-2); distal humerus GSP/MSM-180-2; proximal and mid femur GSP/MSM-294-2, part of distal femur GSP/MSM266-2; mid humerus GSP/MSM-289-2, humerus part GSP/MSM-498-2; proxim- 
al partial humerus GSP/MSM-288-2 (proximal most and lateral part eroded), mid humerus GSP/MSM-290-2, mid tibia GSP/MSM-286-2; proximal and mid femur GSP/MSM-69-2, with distal condyles GSP/MSM-272-2 and GSP/MSM265-2; distal fibula GSP/MSM-183-2; part of distal femur ? GSP/MSM-233-2; caudal vertebrae GSP/MSM-16-2, GSP/MSM-793-2; left proximal and mid femur GSP/MSM-69-2; right proximal femur GSP/MSM-294-2; right femur in proximal femur GSP/MSM-294-2, mid femur GSP/MSM-293-2 and distal femur GSP/MSM-266-2 parts; proximal and mid partial humerus GSP/MSM-289-2 and distal humerus GSP/MSM-180-2; proximal partial humerus GSP/MSM-288-2 (proximal most and lateral part eroded), mid humerus GSP/MSM-290-2; a partial right tibia including proximal slender tibia GSP/MSM-72-2 and distal tibia GSP/MSM-186-2; proximal and mid left tibia GSP/MSM-286-2 (Figure 9).

Pakisaurus balochistani referred materials from Top Kinwa 16 consists of caudal vertebrae GSP/MSM-17-16, GSP/MSM-510-16, GSP/MSM-154-16; chevron GSP/MSM-330-16, prezygapophyses GSP/MSM-327-16; and proximal ulna GSP/MSM-1032-16. Referred materials from Shalghara 3 include a fractured distal caudal vertebra GSP/MSM-523-3; distal caudal vertebra with horizontal groove on posterior cone GSP/MSM-151-3; proximal pubis with glenoid and fenestra GSP/MSM-366-3; ulna GSP/MSM-748-3; sickle shaped ungual GSP/MSM152-3; possibly thick armour spine GSP/MSM-150-3 (Figure 9).

Referred materials from north Alam 19n (just close to Top Kinwa 16 eastern site) consists of proximal pubis GSP/MSM-403-19n; proximal radius GSP/MSM756-19n; and distal ulna GSP/MSM-628-19n; and caudal vertebrae GSP/MSM758-19n. Further referred materials from south Kinwa 4 include proximal right humerus GSP/MSM-195-4. Referred fossil from East Dolwahi 17 includes proximal rib GSP/MSM-321-13. Further caudal vertebra from Mari Bohri 15 includes GSP/MSM-15-15 (Figure 9).

Locality, horizon and age: Holotype was discovered from south Kinwa 4 (Figure 4 of [1]). Referred materials found from lower Bor 2, north Alam 19n, Mari Bohri 15, south Kinwa 4, Shalghara 3 and Top Kinwa 16 localities of Vitakri dome area (Figure 4 of [1]), and east Dolwahi locality 13 of Dhaola Range (Figure 1), Barkhan district, Balochistan, Pakistan. Host horizon is Vitakri Formation of Fort Munro Group [1] [4] [8] [16] [17]. Age is latest Maastrichtian [4] [12].

Diagnosis: The updated diagnosis and comparisons can be seen in [1] [4].

Description: Pakisaurus balochistani holotypic caudal vertebrae were first reported and described in conference 2004 [9] and later on described and figured in 2006 [12]. Its holotypic elements (other than vertebrae of [12]) from south Kinwa and referred materials from different localities were described briefly in [19]. Its complete holotypic specimens were first figured as Figures 1-3 of [4]. Its updated description and comparisons can be seen in [4], there the prefix GSP/ should be considered in specimen numbering like GSP/MSM-7-15 (instead of MSM-7-15), if already not mentioned. It was formally described in 2021 
[1].

Comparison of Indian and Pakistani titanosaurs: Indian titanosaur taxa are informal and not official, while Pakistani titanosaur taxa are official by the rules of ICZN ([1] and here). Comparison with Indian titanosaurs is problem because these are based only one or two bones like holotype of Titanosaurus indicus is one procoelous and another amphicoelous caudals, Titanosaurus blanfordi is one short and another long caudals, Titanosaurus rahioliensis are isolated teeth (apparently only one tooth) and Jainosaurus septentrionalis is braincase. Slender and narrow crown features of a tooth of $T$. rahioliensis match with the teeth of Gspsaurus, Saraikimasoom, Nicksaurus and Pakisaurus while its same thickness from base to end of crown (except tip) differentiates it from gspsaurids (stocky poripuchian) like Gspsaurus, Saraikimasoom and Nicksaurus. Tooth may belong to pakisaurids (slender titanosaurs) like Pakisaurus, Isisaurus, Sulaimanisaurus and Khetranisaurus. Cylindrical shape of holotypic long centrum of $T$. blanfordi matches with cylindrical nature of Balochisaurus centrum GSP/MSM-834-15 and Gspsaurus centrum GSP/MSM-221-19. Long centrum of T. blanfordi has rounded posterior ball while Balochisaurus has relatively sharp cone of posterior ball and Gspsaurus has restricted articular ball. Length: Height ratio of long and short centra (type series) of T. blanfordi is 2.4 and 1.3 while Balochisaurus centrum has 1.8 and Gspsaurus centrum has 1.6. Tallness feature of a caudal of Laplatasaurus madagascariensis matches with caudals of Gspsaurus and Pakisaurus, and other squarish caudal matches with Balochisaurus and Sulaimanisaurus. Holotypic caudal vertebrae of T. indicus are also different than Pakisaurus. Slender and tall features of caudal of $T$. indicus distinguished from stocky and relatively less tall caudal of Pakisaurus. There is a ventral median ridge in caudal of T. indicus which is not found in Pakisaurus. Other caudal of T. indicus is amphicoelous while Pakistani titanosaurs have no amphicoelous vertebra. If holotypic one procoelous and other amphicoelous vertebrae of $T$. indicus are associated as single individual then it belongs to lithostrotian (distal tail is not procoelous) as suggested by Mickey Mortimer, while Pakisaurus is poripuchian (complete tail vertebrae are procoelous) titanosaur. Referred flat proximal tibia of $T$. indicus shows affinity to both Sulaimanisaurus and Pakisaurus. The typical distal tibia is missing in $T$. indicus. Squarish caudal vertebrae and distal humerus without expanded radial condyle of Isisaurus match with relevant fellow of $\mathrm{Su}^{-}$ laimanisaurus but for confirmation typical tibia is missing in Isisaurus while flat tibia was assigned to Sulaimanisaurus [1]. Many bones were assigned to Jainosaurus which have no any key elements for distinguishing (except braincase). Jainosaurus bones are chimeraic discussed on page 435 of [4].

\subsection{Theropod Dinosaurs from the Vitakri Formation of Pakistan}

Vitakrisaurus saraiki [1] was reported in 2010 [16] and formally figured (Figure 9 of [1]) and described in 2021 [1]. Its cranial materials diagnosis and description is mentioned in 2021 [1] while its postcranial material diagnosis and de- 
scription was presented in 2020 [5], there the prefix GSP/ should be considered in specimen numbering like GSP/MSM-303-2 (instead of MSM-303-2), if already not mentioned.

Vitakridrinda sulaimani [1] was initially reported in conference 2004 [9] and 2006 [12], and formally figured (Figure 9 of [1]) and described in 2021 [1]. Its cranial materials diagnosis and description is mentioned in 2021 [1] while its postcranial material diagnosis and description was presented in 2020 [5], there the prefix GSP/ should be considered in specimen numbering like GSP/MSM-59-19 (instead of MSM-59-19), if already not mentioned. Here a vertebra GSP/Sangiali1175 (Figure 8) from mid Sangiali 1 (Figure 4 of [1]) is being referred to Vitakridrinda sulaimani due to its same shape vertebra (GSP/MSM-56-1) found from same locality [1] [5].

\subsection{Mesoeucrocodiles from the Cretaceous of Pakistan}

Pabwehshipakistanensis [20], Induszalim bala [1], Sulaimanisuchus kinwai [1] and Mithasaraikistan [1] were reported from the latest Cretaceous of Pakistan. Khuzdarcroco zahri based on poorly recognized rib from marine strata is presented here.

Systematic paleontology;

Crocodyliformes; Mesoeucrocodylia;

Khuzdarcroco zahri new genus and new species (Figure 11).

Etymology: Genus Khuzdar, honors host Khuzdar district, croco, for crocodile. Species zahri, honors the Local Zahri tribe.

Holotype: A partial rib GSP/MSM-1057-K (Figure 11). Fossil housed in the museum of Geological Survey of Pakistan, Quetta.

Referred specimen: One possible egg fragment GSP/MSM-1058-K may belong to Khuzdarcroco zahri or any other genera of mesoeucrocodile.

Type locality, horizon and age: Type locality is half kilometer away south of Khuzdar Cantt (Figure 1) (latitude $27^{\circ} 46^{\prime} 37^{\prime \prime E}$; longitude $66^{\circ} 36^{\prime} 44^{\prime \prime E}$ ) and just near the south of the Karachi-Khuzdar highway. Horizon is marine maroon shale and marl alternated beds of Goru Formation of Parh Group. Age is Early to Middle Cretaceous. Referred egg found from stream near Karkh site 41 may derived from Late Cretaceous Pab and Vitakri formations.

Diagnosis and comparisons: The size of rib (may also be seen as phalanges) match with crocodiliform. Its age provide a link to mesoeucrocodile. Preserved partial rib length is $6 \mathrm{~cm}$, width is $2.5 \mathrm{~cm}$ and depth is $1 \mathrm{~cm}$. It forms low angle arc (Figure 11). The egg (may be nodule) outer shell seams to be a porous with white and grey colors. The inner portion is amorphous. Preserved egg length (which is about half of full egg) is $4 \mathrm{~cm}$, diameters are $3.8 \mathrm{~cm}$ and $4.2 \mathrm{~cm}$.

\subsection{Pterosaur: The Flying Reptile from the Vitakri Formation of Pakistan}

Saraikisaurus minhui [1] was formally figured and described in 2021 [1]. Its detailed comparison and description can be seen in [5]. 


\subsection{Wasaibpanchi damani Bird from Latest Maastrichtian of Pakistan}

Systematic paleontology

Aves; Metornithes; Ornithotharaces; Enantiornithes;

Wasaibpanchidae [1];

Wasaibpanchidae has transversely compressed teeth like Archaeopteryx, Hesperornithidae and Ichthyornithidae. Wasaibpanchidae has trigonal and triconvex relatively less transversely compressed teeth while Archaeopteryx, Hesperornithidae and Ichthyornithidae have flattened teeth. Wasaibpanchidaebore relatively less transversely compressed large teeth while bohaiornithids enantiornitheans bore strongly transversely compressed large, robust and somewhat conical but had sharply pointed tips.

Wasaibpanchi damani [1]; (Figure 12 of [1])

Etymology, holotype, type locality, horizon and age: These are available in [1].

Diagnosis and comparison: Wasaibpanchi shared laterally compressed teeth with all known toothed birds. Wasaibpanchi shared heterodont triangular teeth with enantiornitheans, Archaeopteryx, Hesperornis and Ichthyornis. Wasaibpanchi broad, conical and transversely compressed teeth shared with Archaeopteryx, Hesperornis and Ichthyornis. Wasaibpanchi consist of broad expanded root like the Archaeopteryx, Hesperornis and Ichthyornis. Wasaibpanchi has trigonal and triconvex relatively less transversely compressed teeth while Archaeopteryx, Hesperornis and Ichthyornis have flattened teeth (transversely more compressed teeth). Wasaibpanchi has teeth with asymmetrical anterior and distal sides. The teeth of Wasaibpanchi seem to be constricted at the base because of preserved broken nature and have no articulated jaw portions while crocodilians have less constricted and theropods have no constricted at the base of teeth. Wasaibpanchi seems to have swollen and very broad base while theropod has no swollen base. Wasaibpanchi bore long relatively less transversely compressed teeth while fish eater longipterygids enantiornitheans bore long relatively more transversely compressed teeth. Wasaibpanchi bore long teeth while mud probers longipterygids enantiornitheans bore small teeth. Wasaibpanchi bore long conical teeth while Pengornis bore short blunted teeth to eat arthropods. Wasaibpanchi bore relatively less transversely compressed large teeth while bohaiornithids enantiornitheans bore strongly transversely compressed large, robust and somewhat conical but had sharply pointed tips. Wasaibpanchi bore long teeth while Gobipteryx has no teeth. Wasaibpanchi has two bony layers (outer white and inner blue layer) which are enveloped on large central cavity, while Archaeopteryx has flattened enamel crown set upon a wider semi elliptical bony base. Its larger teeth cavity is enveloped by blue thin enamel layer and then outer thin white enamel layer, while theropods and mesoeucrocodiles from Pakistan have relatively thick enamel on short core cavity. Wasaibpanchi characterized by relatively less transversely compressed and large trigonal and triconvex teeth with asymmetric 
anterior and distal ends. Further in Indo-Pakistan subcontinent (South Asia) no any latest Maastrichtian bird was reported previously. See other detail in [1].

\subsection{Wadanaang kohsulaimani Snake from the Vitakri Formation of Pakistan}

Wadanaang kohsulaimani [1] snake was formally described in 2021 [1].

\subsection{Zahrisaurus Plesiosaur from Jurassic Chiltan Limestone of Pakistan}

Systematic Paleontology

Plesiosauria;

Zahrisaurus kilmoolai new genus and new species (Figure 10)

Holotype: Trunk body with ribs GSP/MSM-99-K (Figure 10), (Figure 5 of [6]). Fossil housed in the museum of Geological Survey of Pakistan, Quetta.

Type locality, horizon and age: Holotypic body cross section is found as fragmentary in the Chotok type locality 45 (latitude $28^{\circ} 09^{\prime} 12 " \mathrm{~N}$; longitude $67^{\circ} 07^{\prime} 41^{\prime \prime} \mathrm{E}$ ) of Moola river area (Figure 1), Khuzdar, Balochistan. Its horizon possibly is upper part of Chiltan Limestone of Sulaiman Group. Its age is Late Jurassic [6] [16].

Etymology: Genus Zahri, honors host Zahri tribe, saurus, Greek for reptile. Species kil, honors the host Kil Locality area and moolai, honors the host Moola River.

Diagnosis and comparison: It was described in detail in [6], there the prefix GSP/should be considered in specimen number GSP/MSM-99-K (instead of MSM-99-K). The ribs curving structure matches with Occitanosaurus tournemirensis, Plesiopharos moelensis and Muraenosaurus sp.

\subsection{Fishes from the Paleozoic and Mesozoic Strata of Pakistan}

\subsubsection{Muzaffarabadmachli Fish from the Cambrian of Pakistan} Systematic paleontology

Fishes; Agnatha;

Muzaffarabadmachli abbottabadi new genus and new species

(Figure 10); (Figure 5 of [6])

Holotype: Body section GSP/MSM-1-Muzaffarabad (Figure 10) housed in lawn concrete chip of GSP Muzaffarabad office hired from Tariq Abbassi, upper Chattar.

Type locality, horizon and age: Locality is upper Chattar (latitude $34^{\circ} 20^{\prime} 47^{\prime \prime} \mathrm{N}$; longitude $73^{\circ} 28^{\prime} 15^{\prime \prime E}$ ), Muzaffarabad. Horizon is dolomitic limestone of Abbottabad Formation. Its age is Cambrian [6].

Etymology: Genus Muzaffarabad, honors host Muzaffarabad city and machli, Urdu for fish. Species abbottabadi, honors host Abbottabad Formation.

Diagnosis and comparison: It can be seen in [6].

\subsubsection{Kahamachli Fish from the Latest Cretaceous of Pakistan}

Systematic paleontology 


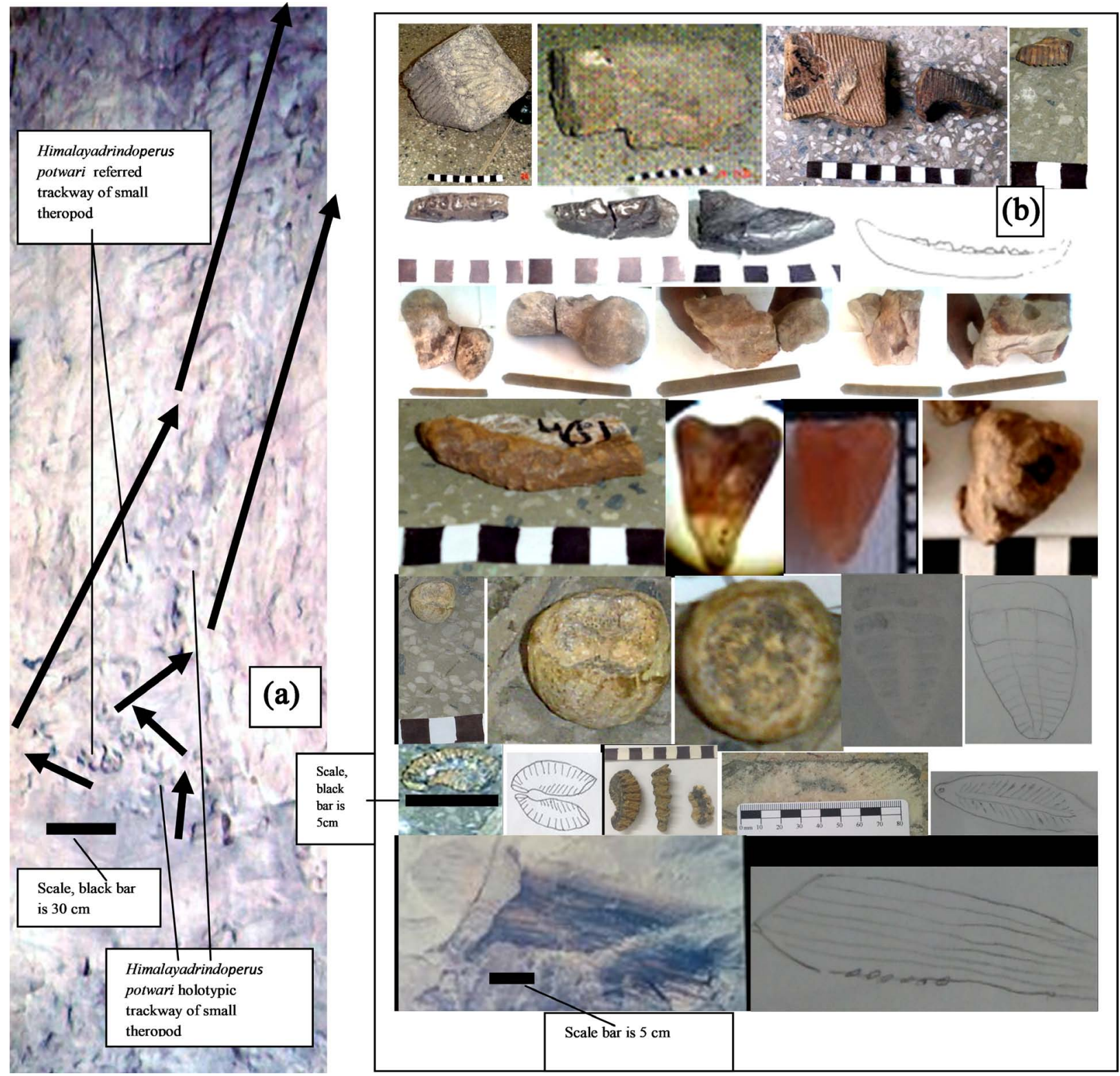

Figure 10. (a)Himalayadrindoperus potwari holotypic GSP/MSM-6-Malakhel and referred GSP/MSM-7-Malakhel trackways from Malakhel. (b) Row 1, p1, Zahrisaurus kilmoolai holotype body section GSP/MSM-99-K from Chotok 45 (Figure 1); p2, Baradarakht goeswangai holotype thick stem GSP/MSM-158-6 from Goes Wanga Pass 6 (Figure 1); p3, Karkhimachli sangiali holotype section GSP/MSM-162-K and referred sections GSP/MSM-163-K; and p4, K. sangiali referred fossil GSP/MSM-164-K from south Karkh 40 (Figure 1). Row 2, Bolanicyon shahani holotypic dentary GSP/MSM-1068-Mach from Mach, Kachi district, Balochistan. Row 3, Gomphotherium buzdari holotype proximal femur (mosaic of GSP/MSM-MSID-1 and GSP/MSM-MSID-2); distal femur (mosaic of GSP/MSM-MSID-3 and GSP/MSM-MSID-5) and proximal tibia GSP/MSM-MSID-4 from Mahoi 35 (Figure 1). Row 4, p1, Mirvitakriharan haji holotype dentary GSP/MSM-141-4s from south Kinwa 4 (Figure 4 of [1]) and p2-4, referred teeth GSP/MSM-1-Laki Bara (length 4mm) in 2 views from Bara nala, Jamshoro, Sindh and GSP/MSM-1100-19 from Alam 19 (Figure 4 of [1]). Row 5, p1-3, Kilgai moolakharzaniholotypic tooth GSP/MSM-165-K in 3 views from Kil 44 (Figure 1); p4, 5, Moolatrilo chotoki holotypic shell section GSP/MSM-1076-K (total length is $20 \mathrm{~cm}$ ) with line drawing from Chotok 45 (Figure 1). Row 6, p1,2, Pakiring kharzani holotypis shell GSP/MSM-1073-K image and line drawing; p3, holotypic shell GSP/MSM-1073-K and two referred shell GSP/MSM-1074-K and GSP/MSM-1075-K from north Kharzan 43 (Figure 1); p4, 5, Muzaffarabadmachli abbottabadi image and line drawing of holotype body section GSP/MSM-1-Muzaffarabad from Muzaffarabad. Row 7, Kahamachli harrandlundi image and line drawing of lower jaw with teeth impression GSP/MSM-2-Kaha Harrand from Kaha rud 31 (Figure 1). Scale each black digit is $1 \mathrm{~cm}$. 
Fishes; Catfish (freshwater);

Kahamachli harrandlundi new genus and new species (Figure 10)

Holotype: Body section GSP/MSM-2-Kaha Harrand (Figure 10) housed in field.

Type locality, horizon and age: Type locality is the southern bank of Kaha nala 31 locality (N29 $34^{\prime} 37^{\prime \prime}$; E69 $9^{\circ} 7^{\prime} 24^{\prime \prime}$ ) (Figure 1) of Harrand Lundi Saidan and Maarri area. Horizon is upper part of Pab Sandstone [16]. Age is Maastrichtian [16].

Etymology: Genus Kaha, honors host Kaha Rud/nala, machli, Urdu for fish. Species harrand, honors the host historic Qila (Fort) of Harrand, and Lundi, honors Lundi Saidan town of Rajanpur district, South Punjab (Saraikistan).

Diagnosis and comparison: It can be seen in [6].

\subsubsection{Karkhimachli Fish from the Latest Maastrichtian of Pakistan}

Systematic paleontology

Fishes;

Karkhimachli sangiali new genus and new species (Figure 10)

Holotype: Fragmentary body cross section GSP/MSM-1062-K (Figure 10). Fossil housed in the museum of Geological Survey of Pakistan, Quetta.

Referred specimens: Referred fossils GSP/MSM-1063-K and GSP/MSM-1064-K, and silicified tooth? (GSP/MSM-1-Laki Bara) (Figure 10) (Figure 5 of [6]).

Fossils housed in the museum of Geological Survey of Pakistan, Quetta.

Type locality, horizon and age: The holotypic and referred fossils were found as fragmentary on Sangiali formation of south Karkh type locality 40 (Figure 1) $\left(27^{\circ} 42^{\prime} 14^{\prime \prime N} ; 67^{\circ} 09^{\prime} 10^{\prime \prime} \mathrm{E}\right)$ of Khuzdar district, Balochistan [15]. It is possible these fossils may be derived from adjoining Vitakri and Pab Formations of Fort Munro Group [16]. Its age is Maastrichtian-Earliest Paleocene [6] [16].

Etymology: Genus Karkhi, honors the host Karkh area, and machli, Urdu for fish. Species K. sangiali, honors the host Sangiali Formation.

Diagnosis and comparison: It can be seen in [6].

\subsection{Mammalian Fossils Found from Pakistan}

\subsubsection{Mammalia Evidences from Latest Cretaceous of Pakistan} Systematic paleontology

Mammalia; Perissodactyla; Hippomorpha;

Mirvitakriharan haji new genus and new species (Figure 10); (Figure 4 of [6])

Holotype: Partial dentary GSP/MSM-141-4s (Figure 10); (Figure 4 of [6]. Fossil housed in the museum of Geological Survey of Pakistan, Quetta.

Referred specimens: Teeth GSP/MSM-1-Laki Bara and GSP/MSM-1100-19 (Figure 10). Fossils housed in museum of Geological Survey of Pakistan, Quetta.

Locality, horizon and age: Holotypic dentary found from south Kinwa $4 \mathrm{~s}$ (latitude $29^{\circ} 41^{\prime} 00^{\prime \prime} \mathrm{N}$; longitude $69^{\circ} 23^{\prime} 10^{\prime \prime} \mathrm{E}$ ) (Figure 4 of [1]) and referred tooth (GSP/MSM-1100-19) from central Alam 19 locality (Figure 4 of [1]), Barkhan district, Balochistan.Referred tooth (GSP/MSM-1-Laki Bara) from Bara Nai/Nala of 
Laki anticline, Jamshoro district, Sindh. Host horizon is Vitakri Formation of Fort Munro Group [1] [4] [8] [16] [17]. Age is latest Maastrichtian [4] [12].

Etymology: Genus Mirvitakri, honors Mir Muhammad Khetran of Vitakri, haran, Urdu for goat like wild mammal. Species M. haji, honors Haji Ahmad Khetran (field worker) of Rakhni Village, Barkhan district, and Haji Hafeez (Naib Qasid) and Haji Abdullah Jan, Haji Hameed Brohi, Haji Behram Khan and Haji Irfan (drivers) of Geological Survey of Pakistan, Quetta, Balochistan for excellent cooperation and services during most of the fieldworks in the Sulaiman and Balochistan.

Diagnosis and comparison: It is poorly recognized [6]. Mirvitakriharan haji was first described in 2019 [6]. Here teeth are being referred. Teeth seems to be premolar or molar with expanded distal root end.

\subsubsection{Sulaimanitherium dhanotri Basilosaurid from Pakistan}

Systematic paleontology

Mammalia; Cetacea; Archaeoceti; Basilosauridae; Sulaimanitherium [21];

Sulaimanitherium dhanotri [21]

(Figure $1 \&$ Figure 2 of [6]); (Figure 1 of [21])

Holotype: GSP/MSID-1 to GSP/MSID-100 associated fossilized bones/pieces of bones of vertebral series (Figure 1 \& Figure 2 of [6]) of one individual [6]. In specimens numbering of holotype and Figure $1 \&$ Figure 2 of [6] the institution GSP may be prefixed like GSP/MSID-1 to GSP/MSID-100. MSID is after collector M. Shahid Ishaq Dhanotr. Fossils are housed in the museum of Geological survey of Pakistan, Quetta.

Type locality, horizon and age: Its type locality is Zamri 37 (Figure 1) (latitude $31^{\circ} 19^{\prime} 28^{\prime \prime} \mathrm{N}$; longitude $\left.70^{\circ} 11^{\prime} 11^{\prime \prime} \mathrm{E}\right)$, Zamri area, Tehsil Drug, district $\mathrm{Mu}$ sakhel, Balochistan. Host horizon is Drazinda Formation. Age is Middle Eocene [16].

Etymology: Genus Sulaimani, honors host Koh Sulaiman, therium, Greek for beast. Species dhanotri, honors the collector M. Shahid Ishaq Dhanotr.

Diagnosis and comparison: It was first described in 2013 [21]. Its diagnosis, comparison and description can be seen in [6].

\subsubsection{Pakitherium shagalai Rhinoceros from Zhob, Balochistan}

Systematic paleontology

Mammalia; Perissodactyla; Rhinocerotoidea; Pakitherium [21];

Pakitherium shagalai [21]

(Figure 3 of [6]); (Figure 2 of [21])

Holotype: GSP/MSID-201 to GSP/MSID-227 associated fossilized bones/pieces of bones of cranial and postcranial skeleton (Figure 3 of [6]) of one individual [6]. GSP may be prefixed like GSP/MSID-201 to GSP/MSID-227 in specimens of [6]. The fossils are housed in the museum of Geological survey of Pakistan, Quetta.

Locality, horizon and age: Holotypic and referred fossils found from Shagala 
locality (latitude $31^{\circ} 19^{\prime} 44^{\prime \prime N}$; longitude $68^{\circ} 40^{\prime} 19^{\prime \prime E}$ ), Kamardin Kareez, Zhob. Host horizon is Shagala Formation of Shagala Group. Its age is the Early Eocene [6].

Etymology: Genus Paki, honors the Pakistan, therium, Greek for beast (dangerous animal). Species $P$. shagalai, honors the host Shagala Formation, area and town.

Diagnosis and comparison: It was first described in 2013 [21]. Its diagnosis, comparison and detail description can be seen in [6].

\subsubsection{Buzdartherium gulkirao Rhinoceros from South Punjab (Saraikistan)}

Systematic paleontology

Mammalia; Perissodactyla; Rhinocerotoidea;

Buzdartherium gulkirao new genus and new species

(Figure 11) (Figure 12); (Figure 3 of [6])

Holotype: Cranial and postcranial specimens GSP/MSM-1-Taunsa to GSP/ MSM-37-Taunsa (Figure 11). The close occurrence, relevant sizes and no duplication tells their association with a single individual. GSP may be prefixed like GSP/MSM-1-Taunsa to GSP/MSM-37-Taunsa in specimens in [6]. The fossils are housed in the museum of Geological survey of Pakistan, Quetta.

Referred specimens: Limb elements (GSP/MSM-RA-38-Taunsa to GSP/MSMRA-60-Taunsa) (Figure 12) collected and hosted by Rao M. Ayub (belongs to Khoshab) of Pakistan Atomic Energy Commission, Taunsa (Dera Ghazi Khan).

Locality, horizon and age: Holotypic fossils found from Gulki locality 36 (Figure 1) (latitude $30^{\circ} 42^{\prime} 26^{\prime \prime N}$; longitude $70^{\circ} 29^{\prime} 16^{\prime \prime E}$ ), Tehsil Taunsa, district Dera Ghazi Khan, South Punjab (Saraikistan). The referred fossils may be collected from Middle Eocene to Miocene of Taunsa area. Host horizon is Chitarwata Formation of Vihowa Group. Host is ferruginous conglomeratic beds (just below the $5-10 \mathrm{~m}$ thick terrestrial silica sand). Age is Oligocene (35-30 Million years ago/Mya) [16].

Etymology: Genus Buzdar, honors the host Buzdar tribe, therium, Greek for beast. Species Gulki, honors host Gulki area, and rao, honors the collector Rao M. Ayub.

Diagnosis, comparison and description: Its limb, fore and hind foot elements like 3 metacarpal and 3 metatarsals and associated unguals are stout (Figure 12). Its other comparison and description found in [6].

\subsubsection{Gomphotherium buzdari Proboscidean from South Punjab (Saraikistan) \\ Systematic paleontology \\ Mammalia; Proboscidea; Gomphotherium; \\ Gomphotherium buzdari new species}

(Figure 10); (Figure 4 of [6])

Holotype: Proximal femur (mosaic of GSP/MSM-MSID-1 and GSP/MSMMSID-2), distal femur (mosaic of GSP/MSM-MSID-3 and GSP/MSM-MSID-5), 


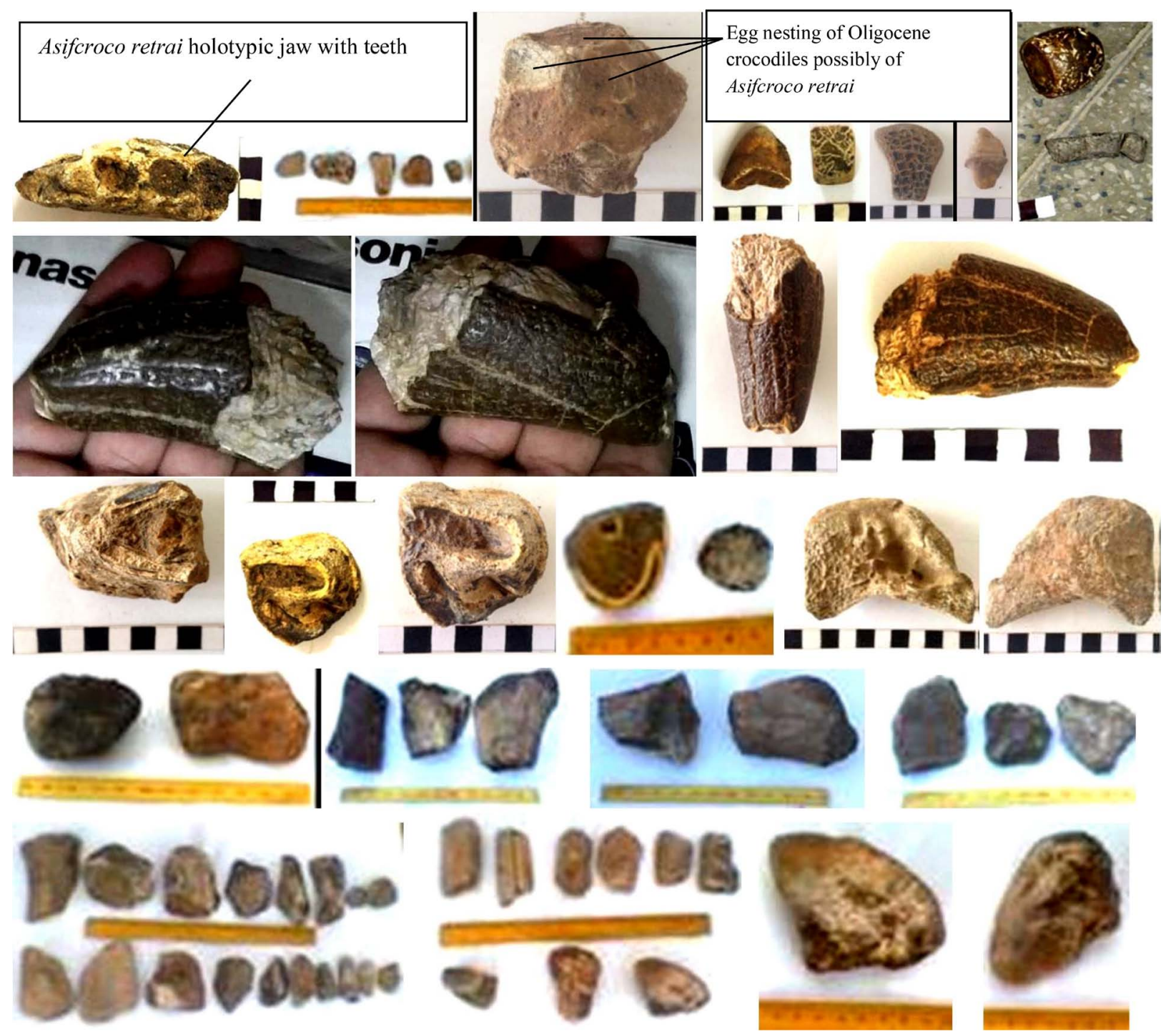

Figure 11. Asifcroco retrai holotype (Row 1, p1-2) and referred (Row 1, p3-7) fossils found from Gulki area 36 (Figure 1) and Khuzdarcroco zahri holotype (Row 1, p8, lower) from Khuzdar Cantt 47 and referred specimen (Row 1, p8, upper) from east Karkh 41 (Figure 1). Buzdartherium gulkirao holotypic fossils (GSP/MSM-1-Taunsa to GSP/MSM-37-Taunsa and GSP/MSM-51Taunsa; Rows 2-5) found from Gulki area 36 (Figure 1) of Taunsa-Gulki section, Tehsil Taunsa, District D. G. Khan, South Punjab (Saraikistan). Row 1, p1,jaw GSP/MSM-46-Taunsa; p2,vertebra GSP/MSM-41-Taunsa, armor GSP/MSM-42-Taunsa, ulna GSP/MSM-43-Taunsa, humerus GSP/MSM-44-Taunsa, and bone fragment GSP/MSM-45-Taunsa; p3, egg nesting with three eggs GSP/MSM-47-Taunsa; p4, egg GSP/MSM-48-Taunsa; p5, armor bone GSP/MSM-49-Taunsa; p6, armor bone GSP/MSM-50Chamalang; p7, tooth GSP/MSM-51-Kharzan Moola; p8, partial rib GSP/MSM-1057-K; and egg GSP/MSM-1058-K. Row 2, tusk tooth GSP/MSM-1-Taunsa in 4 views. Row 3, p1,tooth GSP/MSM-2-Taunsa; p2,3, premolar GSP/MSM-3-Taunsa; p4, premolar GSP/MSM-3-Taunsa and tooth cross section GSP/MSM-4-Taunsa; p5,6, lacrimal GSP/MSM-51-Taunsa. Row 4, p1,two vertebrae GSP/MSM-5-Taunsa and GSP/MSM-6-Taunsa; p2, mid humerus GSP/MSM-7-Taunsa, ulna GSP/MSM-10-Taunsa and proximal femur GSP/MSM-13-Taunsa; p3, ulna GSP/MSM-10-Taunsa and proximal femur GSP/MSM-13-Taunsa; p4, proximal humerus GSP/MSM-9-Taunsa, pubis cross section GSP/MSM-12-Taunsa, proximal pubis GSP/MSM-11-Taunsa; Row 5, p1, upper row, rib GSP/MSM-8-Taunsa, neural arches/spines (GSP/MSM-14-Taunsa to GSP/MSM-18-Taunsa), tooth cross section GSP/MSM-4Taunsa and premolar GSP/MSM-3-Taunsa; Lower row, proximal ischium GSP/MSM-19-Taunsa, ischium cross section GSP/ MSM-20-Taunsa, femur cross section GSP/MSM-21-Taunsa, bone pieces/fragments GSP/MSM-22-Taunsa to GSP/MSM-28Taunsa, p2, upper row, phalanges GSP/MSM-29-Taunsa to GSP/MSM-34-Taunsa, lower row, carpal/astragalous/tarsal MSM-35Taunsa, metacarpal/metatarsal GSP/MSM-36-Taunsa and Ungual/Toe GSP/MSM-37-Taunsa; p3,4, ungual/toe (GSP/MSM-37Taunsa) in 2 views. Scale, every black or white digit is $1 \mathrm{~cm}$. Full yellow coloured scale is about $30 \mathrm{~cm}$. 

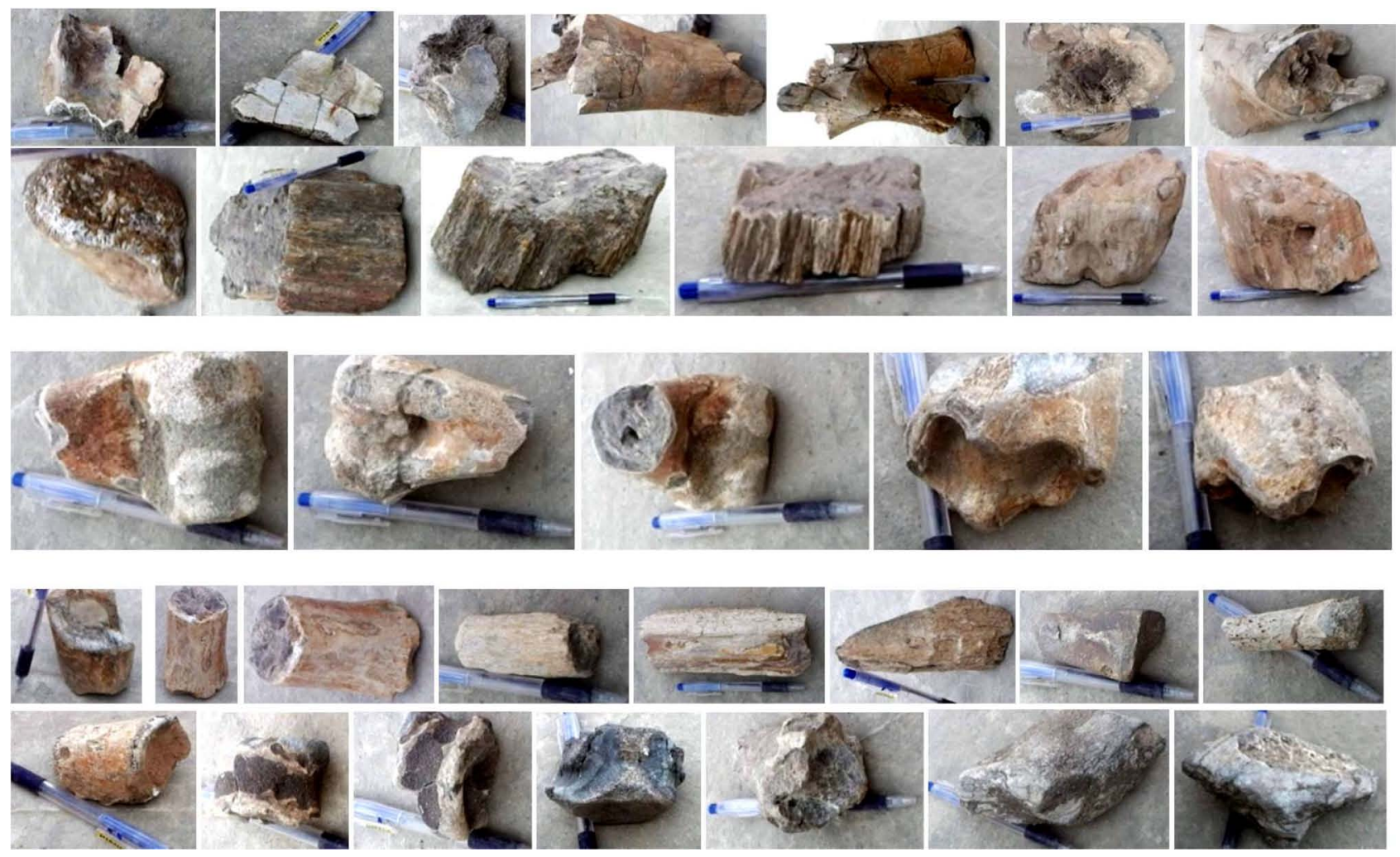

Figure 12. Buzdartherium gulkirao referred fossils (limb and fore foot and hind foot bones) from Taunsa area (Mahoi-Gulki area) (Figure 1), Dera Ghazi Khan, South Punjab. Row 1, p1, proximal fibula GSP/MSM-RA-38-Taunsa; humerus or scapular parts GSP/MSM-RA-39-Taunsa and GSP/MSM-RA-40-Taunsa; mid humerus GSP/MSM-RA-41-Taunsa in 4 views. Row 2, Ankle/wrist bones GSP/MSM-RA-42-Taunsa; GSP/MSM-RA-43-Taunsa, GSP/MSM-RA-44-Taunsa, GSP/MSM-RA-45-Taunsa, and GSP/MSMRA-46-Taunsa (in 2 views). Row 3, fit joint limb and ankle or wrist bones GSP/MSM-RA-47-Taunsa (in 3 views) and GSP/MSMRA-48-Taunsa (in 2 views). Row 4, metatarsal (proximal part GSP/MSM-RA-49-Taunsa and mid and distal part GSP/MSM-RA50-Taunsa in 2 views); metatarsal GSP/MSM-RA-51-Taunsa and GSP/MSM-RA-52-Taunsa; metacarpals GSP/MSM-RA-53Taunsa, GSP/MSM-RA-54-Taunsa and GSP/MSM-RA-55-Taunsa. Row 5, phalanges GSP/MSM-RA-56-Taunsa; GSP/MSM-RA57-Taunsa (in 3 views) and GSP/MSM-RA-58-Taunsa; and unguals/toes GSP/MSM-RA-59-Taunsa and GSP/MSM-RA-60-Taunsa. Scale, pen is about $14 \mathrm{~cm}$.

and proximal tibia GSP/MSM-MSID-4 (Figure 10) (Figure 4 of [6]). The fossils are housed in the museum of Geological survey of Pakistan, Quetta.

Locality, horizon and age: Mahoi type locality 35 (Figure 1) (latitude $30^{\circ} 42^{\prime} 12^{\prime \prime} \mathrm{N}$; longitude $70^{\circ} 30^{\prime} 20^{\prime \prime} \mathrm{E}$ ) is located in eastern limb of Zinda Pir anticline under the territory of Tehsil Taunsa, District Dera Ghazi Khan, South Punjab (Saraikistan). Its horizon is Litra Formation of Vihowa Group [16]. Its age is Miocene [16].

Etymology: Species G. buzdarihonors the host Buzdar tribe.

Diagnosis and comparison: These were described in detail in [6].

\subsubsection{Kilgai moolakharzani Proboscidean from South Punjab (Saraikistan)}

Systematic paleontology

Mammalia; Protosirenidae;

Kilgai moolakharzani new genus and new species 
(Figure 10); (Figure 4 of [6])

Holotype: A fragmentary typical tooth GSP/MSM-1065-K (Figure 10). The fossil is housed in the museum of Geological survey of Pakistan, Quetta.

Locality, horizon and age: Kil type locality 44 (Figure 1) $\left(28^{\circ} 08^{\prime} 15^{\prime \prime} \mathrm{N}\right.$; $\left.67^{\circ} 08^{\prime} 49^{\prime \prime E}\right)$ is located in Tehsil Kharzan Moola, District Khuzdar. Its possible horizon is Shaheed Ghat Formation of Chamalang Group [6] [16]. Age is Early Eocene [15].

Etymology: Genus Kil, honors host Kil locality, and gai, Urdu for cow. Species moola, honors the host Moola River, and kharzani, honors host Kharzan Moola area.

Diagnosis and comparison: These were described in detail in [6].

\subsubsection{Bolanicyon shahani Mammal from Early Eocene of Pakistan}

Systematic paleontology

Mammalia; Perissodactyla; Hippomorpha

Bolanicyon shahani new genus and new species (Figure 10); (Figure 4 of [6])

Holotype: Lower jaw with teeth and angular (GSP/MSM-1068-Mach) (Figure 10). The fossil is housed in the museum of Geological survey of Pakistan, Quetta.

Locality, horizon and age: Its locality is Gishtari area of Mach (possibly latitude $29^{\circ} 48^{\prime} 24^{\prime \prime N}$; longitude $67^{\circ} 17^{\prime} 58^{\prime \prime E}$ ), District Kachi, Balochistan, Pakistan. Its possible horizon is Toi Formation of Chamalang Group. Its age is Early Eocene [15].

Etymology: Genus Bolani, honors the host Bolan river, and cyon, for carnivore dog. Species shahani, honors the presenter or collector coal miner Gul Zaman Shahani.

Diagnosis and comparison: These were described in detail in [6].

\subsection{Asifcroco retrai Eucrocodile from Taunsa Area, South Punjab}

Systematic paleontology

Crocodyliformes; Eucrocodiles (Eusuchian); Crocodilidae

Asifcroco retrai new genus and new species

(Figure 11); (Figure 4 of [6])

Holotype: Jaw GSP/MSM-46-Taunsa; vertebra GSP/MSM-41-Taunsa: armor bone GSP/MSM-42-Taunsa: proximal ulna GSP/MSM-43-Taunsa; proximal humerus GSP/MSM-44-Taunsa; bone fragment GSP/MSM-45-Taunsa (Figure 11). These fossils housed in the Museum of Geological Survey of Pakistan, Quetta.

Referred specimens: possible egg nesting GSP/MSM-47-Taunsa; Egg GSP/ MSM-48-Taunsa; armor GSP/MSM-49-Taunsa; armor GSP/MSM-50-Chamalang, tooth GSP/MSM-51-Kharzan Moola (Figure 11). These fossils housed in the Museum of Geological Survey of Pakistan, Quetta.

Locality, horizon and age: Holotypic and referred fossils found from Gulki locality 36 (Figure 1) (latitude $30^{\circ} 42^{\prime} 26^{\prime \prime N}$; longitude $70^{\circ} 29^{\prime} 16^{\prime \prime E}$ ), Tehsil Taunsa, district D.G. Khan, South Punjab (Saraikistan). The host horizon is Chitarwata 
Formation of Vihowa Group. The host is the ferruginous conglomeratic beds (just below the 5-10 meters $/ \mathrm{m}$ thick silica sand) of terrestrial origin. Its age is Oligocene [6] [16].

Etymology: Genus Asifcroco, honors M. Asif Malkani who partially supported this discovery and the visit of Mahoi-Zin, Taunsa-Gulki and Sata post sections of Taunsa area. Species retrai, honors his native Retra town of Dera Ghazi Khan [6].

Diagnosis and comparison: These detail description can be seen in [6], there the prefix GSP/should be considered in specimen numbering like GSP/MSM-46Taunsa (instead of MSM-46-Taunsa).

\subsection{Cretaceous Tree from the Pab Formation, Balochistan Province, Pakistan}

Systematic paleontology

Planta; Gymnosperm;

Baradarakht goeswangai new genus and new species

(Figure 10); (Figure 6 of [6])

Holotype: A large stem wood fossil GSP/MSM-158-6 (Figure 10) of a single tree. The fossil is housed in the Museum of Geological Survey of Pakistan, Quetta.

Locality, horizon and age: Holotypic fossil was found in the materials broken for road construction at Goes Wanga Pass locality 6 (Figure 1) $\left(29^{\circ} 43^{\prime} 35^{\prime \prime} \mathrm{N}\right.$; $69^{\circ} 30^{\prime} 59^{\prime \prime E}$ ), district Barkhan, Balochistan. Host horizon belongs to Dhaola member of the Pab Formation of Fort Munro Group [8] [16]. Its age is the Maastrichtian [4].

Etymology: GenusBara, Urdu for big, and Darakht, Urdu for tree. The species goeswangai, honors the Goes Wanga Pass locality of Dhaola Range.

Diagnosis and comparison: Baradarakht goeswangai shared with gymnosperm Plant on the basis of large and thick stem and its Maastrichtian age. Baradarakht goeswangai is represented by thick, large, circular and fibrous structures. This is the first tree reported from the Mesozoic of Pakistan. Its detail can be seen in [6] [15].

\subsection{Invertebrates Found from Pakistan}

\subsubsection{Pakiring kharzani Bivalve from Balochistan, Pakistan}

Systematic paleontology

Bivalvia; Pelecypoda; Hippuritida;

Pakiringia new taxon

Etymology: Paki, honors the host Pakistan, ringia, for its ring shaped.

Definition: Pakiring, its most recent common ancestor and all of its descendants.

Included species: Pakiring kharzani.

Diagnosis: Features same as included species.

Pakiring kharzani new genus and new species 
(Figure 10); (Figure 6 of [6])

Holotype: Holotypic body fossil GSP/MSM-1073-K (Figure 10). The fossil housed in the Museum of Geological Survey of Pakistan, Quetta.

Referred specimen: Referred fossils GSP/MSM-1074-K and GSP/MSM1075-K (Figure 10). Fossils housed in Museum of Geological Survey of Pakistan, Quetta.

Locality, horizon and age: Pakiring kharzani holotype and referred fossils were found in the brown colored lateritic beds $\left(28^{\circ} 04^{\prime} 22^{\prime \prime} \mathrm{N} ; 67^{\circ} 06^{\prime} 38^{\prime \prime} \mathrm{E}\right)$ at the southern bank of a branch stream of Moola River located just north of Kharzan town 43 (Figure 1). Kharzan Moola is a Tehsil of Khuzdar district, Balochistan. Horizon is the Vitakri Formation of Fort Munro Group [8]. Its age is Latest Maastrichtian [4].

Etymology: Genus Paki, honors the host Pakistan, ring, for its ring shaped. Species Pakiring kharzani honors the host Kharzan Moola Tehsil of Khuzdar district.

Diagnosis and comparison: Pakiring kharzani shared with Bivalvia on the basis of seemingly two valves. Pakiring kharzani is characterized by rugose ornamented ropes on its ring shaped body. On this basis it is differentiated from others bivalves. It is unique invertebrate found in Pakistan. The detail can be seen in [6].

\subsubsection{Pakiwheel karkhi Nautiloid from Balochistan, Pakistan}

Systematic paleontology

Mollusca; Cephalopoda; Nautiloidea:

Pakiwheel new genus

Etymology: Genus Paki, honors host country Pakistan, wheel, for its wheel shape.

Included species: Pakiwheel karkhi and Pakiwheel Vitakri.

Diagnosis: Features same as included species.

Pakiwheel karkhi new species

(Figure 13); (Figure 6 of [6])

Holotype: Complete shell fossil GSP/MSM-1071-K (Figure 13). Fossil housed in the Museum of Geological Survey of Pakistan, Quetta.

Referred specimens: A grave yard including many fossils found in volcaniclastic beds in Pir Bari road of Karkh 41 (Figure 1) area. Referred fossils found in the field.

Type locality, horizon and age: Pakiwheel karkhi on Pir Bari road, Karkh

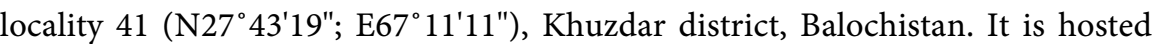
by dark green volcaniclastic sandstone of Sangiali Formation. Age is Early Paleocene.

Etymology: Species karkhi, honors the host Karkh locality.

Diagnosis and comparison: Pakiwheel karkhi shared with Nautiloid Cephalopoda on the basis of spiral shell, fit in age and size. Pakiwheel karkhi is characterized by slender body (transverse width is relatively more and dorsoventral 
depth is relatively low), while the Pakiwheel vitakri which has relatively stockier body size. Its detail description can be seen in [6], there prefix GSP/ be added with specimens.

\subsubsection{Pakiwheel vitakri Nautiloid from Balochistan, Pakistan}

Systematic paleontology

Mollusca; Cephalopoda; Nautiloidea;

Pakiwheel new genus (same as above)

Pakiwheel vitakri new species

(Figure 13); (Figure 6 of [6])

Holotype: Complete shell fossilGSP/MSM-1072-V (Figure 13). Fossil is housed in the Museum of Geological Survey of Pakistan, Quetta.

Referred specimens: Many fossils in volcaniclastic beds in Lower Bor 2 (Figure 4 of [1]) and many fossils in Mat Khetran 21 (Figure 1). Fossils hosted in field.

Type locality, horizon and age: Lower Bor 2 type locality (N29 $41^{\prime} 21^{\prime \prime}$; E $\left.69^{\circ} 22^{\prime} 33^{\prime \prime}\right)$. Horizon is Sangiali Formation [16]. Age is Early Paleocene (Danian) [16].

Etymology: Species vitakri, honors the host Vitakri locality.

Diagnosis and comparison: Pakiwheel vitakri shared with Nautiloid Cephalopoda on the basis of spiral shell, fit in size and age. Pakiwheel vitakri is characterized by stockier body size (transverse width is relatively less and dorsoventral depth is relatively high) than the Pakiwheel karkhi which has slender body. Its detail description can be seen in [6], there the prefix GSP/ may be added in specimens.

\subsubsection{Moolatrilo chotoki Artiopoda Arthropod from Balochistan,} Pakistan

Systematic paleontology

Arthropoda; Artiopoda (Trilobites and close relatives); Trilobita;

Moolatrilo chotoki new genus and new species (Figure 10)

Holotype: Fossil shellGSP/MSM-1076-K (Figure 10) in the field.

Type locality, horizon and age: It is found in the limestone exposed on stream channel in the Chotok 45 Water Spring area (Figure 1) (latitude $28^{\circ} 09^{\prime} 12^{\prime \prime} \mathrm{N}$; longitude $67^{\circ} 07^{\prime} 41^{\prime \prime} \mathrm{E}$ ) on the west of Kil locality. Horizon is Chiltan Limestone of Sulaiman Group. Its age is Triassic-Jurassic [16] but extends upto Permo-Triassic boundary.

Etymology: Genus Moola, honors the Moola river, trilo for trilobite. Species chotoki, honors the host Chotok water spring locality of Kil-Chotok area.

Diagnosis and comparison: Moolatrilo chotoki shared with Trilobita on basis of 12 articulated segments and skeleton body shape. Its description can be seen in [6].

\subsubsection{Mulastarzahri Star Fish from Balochistan, Pakistan}

Systematic paleontology 
Arthropoda; Echinodermata:

Mulastar zahri new genus and new species (Figure 13)

Holotype: A fossil shell GSP/MSM-1070-K (Figure 13). The fossil housed in the Museum of Geological Survey of Pakistan, Quetta.

Type locality, horizon and age: Mulastarzahri on Kharzan-Karkh road,

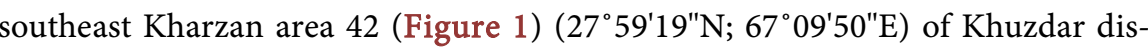
trict. It is found Shaheed Ghat shale of Chamalang Group [16]. Age is Early
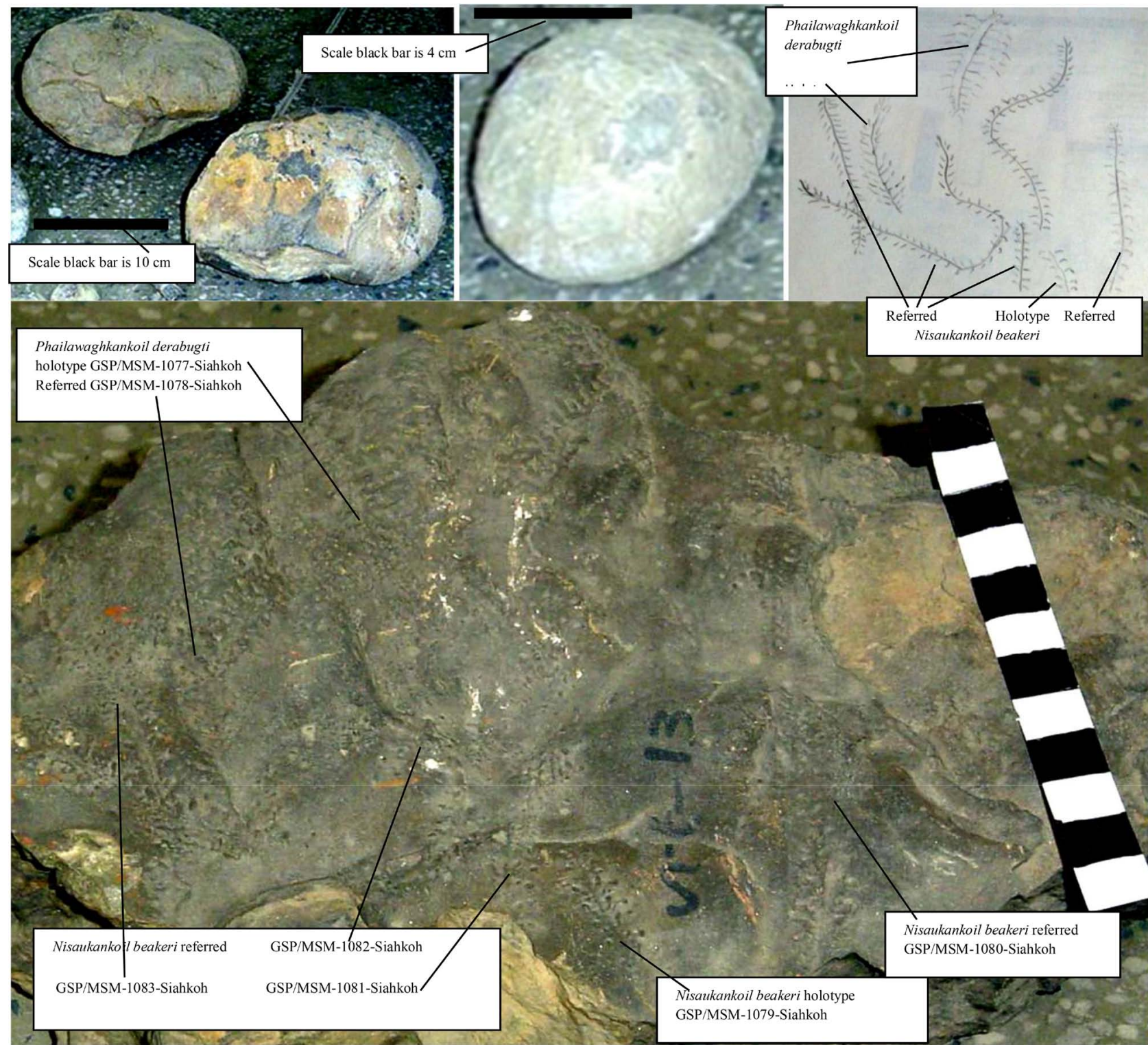

Figure 13. Row 1, p1, Pakiwheel karkhi holotype shell GSP/MSM-1071-K (upper) from Pir Bari road, east Karkh locality 41 (Figure 1); Pakiwheel vitakri shell GSP/MSM-1072-V (lower) from lower Bor 2 (Figure 4 of [1]); p2, Mulastar zahri holotype shell GSP/MSM-1070-K from south east Kharzan 42 (Figure 1); p3, line drawing of following image including Nisaukankoil beakeri and Phailawaghkankoil derabugti. Row 2, a block GSP/MSM-Vit-13 consists of Phailawaghkankoil derabugti (relatively thicker and short skeleton) holotypic shell GSP/MSM-1077-Siahkoh; and referred shell GSP/MSM-1078-Siahkoh and Nisaukankoil beakeri (relatively thin and long skeleton) holotypic shell GSP/MSM-1079-Siahkoh; and referred shells GSP/MSM-1080-Siahkoh, GSP/MSM-1081-Siahkoh, GSP/MSM-1082-Siahkoh, and GSP/MSM-1083-Siahkoh from Siah Koh locality 32 (Figure 1), boarder of Kohlu and Dera Bugti districts, Balochistan province, Pakistan. Scale each black digit is $1 \mathrm{~cm}$. 
Eocene [16].

Etymology: Genus Mula, honors the Mula/Moola river, star, for radiating rays of star shape. Species zahri, honors host Zahri tribe of Khuzdar district, Balochistan.

Diagnosis and comparison: Mulastar zahri shared with Echinodermata on the basis of fivefold radial symmetry. Due to its prominent and distinct minor dotted and ornamented features on double rows on every ray, it is differentiated from others. Its detail description can be seen in [6], there prefix GSP/ be added in specimens.

\subsubsection{Nisaukankoil beakeri Arthropod from Balochistan, Pakistan}

Systematic paleontology

Arthropoda; Chilopoda;

Nisaukankoil beakeri new genus and new species (Figure 13); (Figure 6 of [6])

Holotype: SkeletonGSP/MSM-1079-Siahkoh (Figure 13) in block GSP/MSMVit-13. Fossils housed in Museum of Geological Survey of Pakistan, Quetta.

Referred specimens: Referred skeleton GSP/MSM-1080-Siahkoh, GSP/MSM1081-Siahkoh, GSP/MSM-1082-Siahkoh, and GSP/MSM-1083-Siahkoh (Figure 13) in block GSP/MSM-Vit-13. Fossils housed in the Museum of GSP, Quetta.

Type locality, horizon and age: Holotype is associated with referred specimenfound in Nisau (Kohlu district) and Beaker-Phailawagh (Dera Bugti district) boundary on the northern plunge and axis of Siah Koh anticline locality 32 (Figure 1) $\left(29^{\circ} 34^{\prime} 11^{\prime \prime N} ; 69^{\circ} 29^{\prime} 13^{\prime \prime} \mathrm{E}\right)$ just on the south of vehicle track Nisau to Beaker. Horizon is Rakhi Gaj Formation (sandstone) [19]. Its age is Early Paleocene [19].

Etymology: Genus Nisau, honors the host Nisau area of Kohlu district, Kankoil, Saraiki for coiling in ear (of human).Species beakeri, honors the Beaker area.

Diagnosis and comparison: It shared with Arthropoda on having segmented body. Further it shares with centipede Chilopoda on having numerous legs, long and slender body with fit size. Itis characterized by having relatively small and stocky legs while Phailawaghkankoil derabugti has relatively long and slender legs. Its detail description can be seen in [6], there prefix GSP/ should be added in specimens.

\subsubsection{Phailawaghkankoil derabugti Arthropod from Balochistan}

Systematic paleontology

Arthropoda; Chilopoda;

Phailawaghkankoil derabugti new genus and new species (Figure 13)

Holotype: Fossil skeleton GSP/MSM-1077-Siahkoh (Figure 13) in block GSP/ MSM-Vit-13. Fossil housed in Museum of Geological Survey of Pakistan, Quetta.

Referred specimens: Fossil skeleton GSP/MSM-1078-Siahkoh (Figure 13) found in block GSP/MSM-Vit-13. Fossils housed in the Museum of GSP, Quetta.

Type locality, horizon and age: Holotype is associated with referred specimen found in Nisau (Kohlu district) and Beaker-Phailawagh (Dera Bugti district) boun- 
dary on the northern plunge and axis of Siah Koh anticline locality 32 (Figure 1) $\left(29^{\circ} 34^{\prime} 11^{\prime \prime N} ; 69^{\circ} 29^{\prime} 13^{\prime \prime} \mathrm{E}\right)$ just on the south of vehicle track Nisau to Beaker. Horizon is Rakhi Gaj Formation (sandstone) [19]. Its age is Early Paleocene [19].

Etymology: Genus Phailawagh, honors Phailawagh area, Kankoil, Saraiki for coiling in ear. Species derabugti, honors Dera Bugti district and Bugti tribe.

Diagnosis and comparison: It shared with Arthropoda on having segmented body. Further it shares with centipede Chilopoda on having numerous legs and long body with fit size. It is characterized by long and slender legs while Nisaukankoil beakeri has relatively small and stocky legs. Its detail description can be seen in [6].

\subsection{Archosaurs Footprints and Trackways Found from Mesozoic of Pakistan}

\subsubsection{Malakhelisauroperus Partial Trackways from Latest Jurassic of Pakistan}

Systematic paleontology

Ornithopaonia new ichnotaxon

Etymology: The Ornitho, Greek for bird, paon, Urdu for foot.

Definition: Malakhelisauroperus, Pashtosauroperus, their most recent common ancestor and all of its descendants.

Included species: Malakhelisauroperus mianwali and Pashtosauroperus zhobi.

Diagnosis: Same as features of included species.

Malakhelisauroperus mianwali new ichnogenus and new ichnospecies

(Figure 14)

Etymology: Genus Malakheli, honors host Malakhel area, sauro, Greek for reptile, and per, Saraiki for foot. Species mianwali, honors the host Mianwali district.

Holotype: Partial trackway GSP/MSM-1-Malakhel (Figure 14), housed in field.

Referred materials: Two partial trackways GSP/MSM-2-Malakhel and GSP/ MSM-3-Malakhel associated with holotype (Figure 14) and one isolated footprint GSP/MSM-4-Malakhel found at the southwestern corner of Baroch nala.

Locality, horizon and age: Malakhel locality (Figure 1 of [22]) (Baroch nala; $\left.32^{\circ} 55^{\prime} 50^{\prime \prime} \mathrm{N} ; 71^{\circ} 09^{\prime} 01^{\prime \prime} \mathrm{E}\right)$ found in Mianwali district. Host horizon is upper part of Samana Suk Limestone of Surghar Group. Its age is latest Jurassic (150 - 145 Mya).

Diagnosis and comparison: Its pes characterized by largest three stocky digits and unguals. Its central digit and its ungual directed anteriorly while $1^{\text {st }}$ digit and its ungual directed medially and $3^{\text {rd }}$ digit and its ungual directed laterally. Its footprint is nearly symmetric. Its manus is D-shaped. It was first named as Malasaurus mianwali [22] but renamed as Malakhelisaurus mianwali due to previously engaged name [18]. Its updated description can be seen in [6]. Ornithopaonia assignment to higher level is problem. It may belong to stegosaurian or 


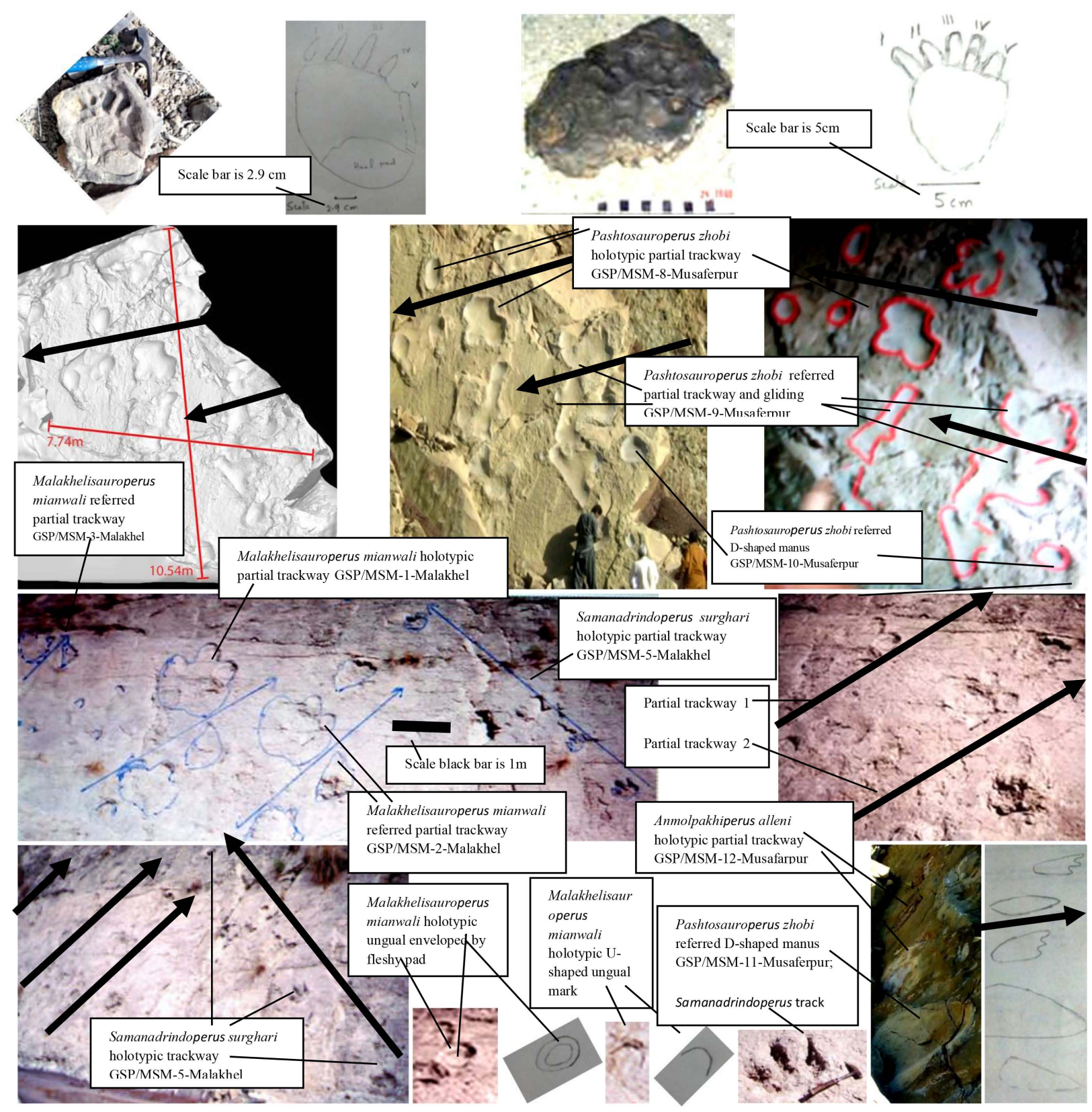

Figure 14. Row 1, p1, 2, Dgkhansauroperus maarri holotypic natural cast of footprint GSP/NS-SJAN-MSM-13-Maarri from Maarri 30 (Figure 1); p3, 4, Chiltansauroperus nicki holotypic footprint GSP/MSM-1067-K from Jhukur Madan peak area 46 (Figure 1). Row 2, Pashtosauroperus zhobi holotypic partial trackway GSP/MSM-8-Musaferpur (upper) and referred partial trackway GSP/MSM-9-Musaferpur (lower), a manus GSP/MSM-10-Musaferpur and isolated manus GSP/MSM-11-Musaferpur (with pterosaur tracks) from Sor Muzghai locality, district Qila Saifullah, Zhob. Scale on $1^{\text {st }}$ photo. Row 3, Malakhelisauroperus mianwali holotypic partial trackway GSP/MSM-1-Malakhel and referred partial trackways GSP/MSM-2-Malakhel and GSP/MSM3-Malakhel and an isolated footprint GSP/MSM-4-Malakhel near coal mine room in south west corner of Broch Nala and Samanadrindoperus surghari holotypic trackway GSP/MSM-5-Malakhel from Baroch nala of Malakhel area (Figure 1 of [22]) of Mianwali. Row 4, p1, Malakhelisauroperus mianwali holotypic and referred partial trackways confronted obliquely by a trackway of large theropod Samanadrindoperus (scale is hammer near the central footprint); p2, 3, ungual mark enveloped by a pad; p4, 5, possibly a hoof mark or may be stressed anterior half of ungual on walking; p6, Samanadrindoperus central footprint, hammer is about 30cm; p7, 8, Anmolpakhiperus alleni holotypic partial trackway GSP/MSM-12-Musaferpur and referred two tracks GSP/MSM-13-Musaferpur and GSP/MSM-14-Musaferpur parallel to holotypic tracks (line drawing tilted) from Musaferpur area, district Qila Saifullah, Zhob division, Balochistan, Pakistan. 
hadrosaurian Ornithischia or may be a stocky ungual bearing titanosauriforms or titanosaurs.

\subsubsection{Pashtosauroperus Partial Trackways from Latest Cretaceous of} Pakistan

Systematic paleontology

Ornithopaonia new ichnotaxon (same as above)

Pashtosauroperus zhobi new ichnogenus and new ichnospecies (Figure 14)

Holotype: Partial trackway GSP/MSM-8-Musaferpur (Figure 14), housed in field.

Referred specimens: Partial trackway GSP/MSM-9-Musaferpur and a manus track GSP/MSM-10-Musaferpur associated with holotype and a manus with digit mark GSP/MSM-11-Musaferpur (Figure 14) found from Sor Muzghai ichnosite.

Locality, horizon and age: Sor Muzghai ichnosite $\left(30^{\circ} 57^{\prime} 36^{\prime \prime} \mathrm{N} ; 69^{\circ} 08^{\prime} 24^{\prime \prime} \mathrm{E}\right)$ found in Musafarpur area of Qila Saifullah district, Zhob, Balochistan. It is reported from the Vitakri Formation (upper part of Pab Formation). Age is Maastrichtian.

Etymology: Genus Pashto, honors the local language of host area, sauro, Greek for reptile, and per, Saraiki for foot. Species P. zhobi, honors host Zhob division.

Diagnosis and comparison: It characterized by largest three stocky digits and oval shaped unguals, and D-shaped manus with no any ungual. Its central ungual directed anteriorly, while $1^{\text {st }}$ digit and its ungual directed medially and $3^{\text {rd }}$ digit and its ungual directed laterally. Its footprint is close to symmetric. Pashtosauroperus was described in 2014 [13] and 2015 [15]. Its updated description can be seen in [6].

\subsubsection{Dgkhansauroperus maarri Footprint from Latest Cretaceous of Pakistan \\ Systematic paleontology}

Sauropaonia new ichnotaxon

Etymology: Sauro, Greek for reptile, paon, Urdu for feet.

Definition: Dgkhansauroperus, Chiltansauroperus, their most recent common ancestor and all of its descendants.

Included species: Dgkhansauroperus maarri, Chiltansauroperus nicki.

Diagnosis: Same as features of included species.

Dgkhansauroperus maarri new ichnogenus and new ichnospecies (Figure 14)

Holotype: Natural cast of footprint GSP/NS-SJAN-MSM-13-Maarri (Figure 14). Holotype is with collector Nasir Somro, Geological Survey of Pakistan, Islamabad.

Locality, horizon and age: It collected from Maarri peak locality 30 (Figure 1) (latitude $29^{\circ} 32^{\prime} 03^{\prime \prime N}$; longitude $69^{\circ} 51^{\prime} 45^{\prime \prime} \mathrm{E}$ ) of Rajanpur district, South Punjab. It is found from the upper part of Pab Formation. Its age is Maastrichtian.

Etymology: Genus Dgkhan, honors the host division Dera Ghazi Khan, sauro, 
Greek for reptile and per, Saraiki for foot. Species maarri, honors host Maarri peak.

Diagnosis and comparison: Its natural cast of right small pes characterized by slender pes with 5 digits; ungual of digits I, II and III directed anterolaterally; digit IV directed laterally; fifth digit is reduced and without toe; and its heel impression is sub-oval. Its detail can be seen in [1] [7]. It was first reported in 2018 [23] and later described in 2019 [6]. It represents slender digits and unguals directing laterally.

\subsubsection{Chiltansauroperus nicki Footprint from the Latest Jurassic of Pakistan \\ Systematic paleontology}

Sauropaonia new ichnotaxon; (same as above) (Chiltansauroperus nicki overlapped as slender digits with Sauropaonia while Ornithopaonia has stocky digits)

Chiltansauroperus nicki new ichnogenus and new ichnospecies (Figure 14)

Holotype: Footprint GSP/MSM-1067-K (Figure 14). This track housed in the museum of Geological Survey of Pakistan, Quetta.

Type Locality, horizon and age: It is found in Madan Jhukur locality 46 (Figure 1) (upper reaches also host fluorite deposit) (latitude $28^{\circ} 15^{\prime} 03^{\prime \prime N}$; longitude $67^{\circ} 06^{\prime} 12^{\prime \prime} \mathrm{E}$ ) of Moola area (north of Kharzan) of Khuzdar district, Balochistan. Horizon is Chiltan limestone. Its age is late Jurassic.

Etymology: Genus Chiltan, honors the host Chiltan Limestone, sauro, Greek for lizard, and per, Saraiki for foot. Species nicki, honors British Journalist Mr. Nicholas Allen (Nick Allen) which helped a lot for preservation of ichnosite and fossils.

Diagnosis and comparison: It characterized by slender digits and unguals. Its central ungual directed anteriorly while $1^{\text {st }}$ and $2^{\text {nd }}$ unguals directed medially and $4^{\text {th }}$ and $5^{\text {th }}$ unguals directed laterally. Chiltansauroperus nicki was first figured in [19] and described in detail in 2021 [1].

\subsubsection{Samanadrindoperus surghari Trackway from the Late Jurassic of Pakistan}

\section{Systematic paleontology}

Theropaonia new ichnotaxon

Etymology: Thero, Greek for beast, paon, Urdu for foot.

Definition: Samanadrindoperus, Himalayadrindoperus, their most recent common ancestor and all of its descendants.

Included species: Samanadrindoperus surghari, Himalayadrindoperus potwari.

Diagnosis: Same as features of included species.

Samanadrindoperus surghari new ichnogenus and new ichnospecies

(Figure 14)

Holotype: A trackway GSP/MSM-5-Malakhel (Figure 14), was housed in field.

Locality, horizon and age: Malakhel ichnite (Figure 1 of [22]) found in $\mathrm{Ba}$ - 
roch nala $\left(32^{\circ} 55^{\prime} 50^{\prime \prime N} ; 71^{\circ} 09^{\prime} 01^{\prime \prime E}\right)$, Mianwali district, Punjab. Host horizon is Samana Suk Formation of Surghar Group. Its age is latest Jurassic (150-145 Mya).

Etymology: Genus Samana, honors the host Samana Suk Limestone, drindo, Saraiki for beast, per, Saraiki for foot. Species surghari, honors host Surghar Range.

Diagnosis and comparison: Ithas moderate/low divarication angle of robust digits II-IV $=c .50^{\circ}$ with straight alignment of digit and claws while Himalayadrindoperus has high divarication angle of slender robust digits II $-\mathrm{IV}=c$. $70^{\circ}-90^{\circ}$ with medially/centrally directed lateral and medial claws. It was first named as Samanadrinda in 2007 [22]. Later on described in 2008 [18] and 2019 [6]. Its comparison and description can be seen in [6].

\subsubsection{Himalayadrindoperus potwari Trackways from Late Jurassic of Pakistan}

\section{Systematic paleontology}

Theropaonia new ichnotaxon (Same as above) (Himalayadrindoperus has slender tridactyle/tridigit overlap with Theropaonia)

Himalayadrindoperus potwari new ichnogenus and new ichnospecies

(Figure 10)

Holotype: A trackway GSP/MSM-6-Malakhel (Figure 10). Holotype was in field.

Referred specimens: A trackway GSP/MSM-7-Malakhel (Figure 10).

Locality, horizon and age: Holotypic and referred trackways found from Baroch nala ( $\left.32^{\circ} 55^{\prime} 39^{\prime \prime N} ; 71^{\circ} 09^{\prime} 00^{\prime \prime E}\right)$ of Malakhel area (Figure 1 of [22]), district Mianwali, Punjab. Host horizon is Samana Suk limestone. Its age is latest Jurassic.

Etymology: Genus Himalaya is honoring the Himalaya Mountain, drindo, Saraiki for beast, per, Saraiki for foot or footmark.

Diagnosis and comparison: Himalayadrindoperus has high divarication angle of slender digits II $-\mathrm{IV}=c .70^{\circ}-90^{\circ}$ with medial deflection of claws while Samanadrindoperus havedivarication angle of digits II - IV $=$ c. $50^{\circ}$ with straight orientation of digit and relevant claw. It is differentiated from other theropod footprints on having high divarication angle. Its comparison and description can be seen in [6]. It was described in 2015 [15] and 2019 [6].

\subsubsection{Anmolpakhiperus alleni Footprints from the Mesozoic of Pakistan} Systematic paleontology

Pteropaonia new ichnotaxon

Etymology: Ptero, Greek for wing or feather, and paon, Urdu for foot.

Definition: Anmolpakhiperus, their most recent common ancestor and all of its descendants.

Included species: Anmolpakhiperus alleni.

Diagnosis: Same as features of included species.

Anmolpakhiperus alleni new ichnogenus and new ichnospecies (Figure 14) 
Holotype: Partial trackway GSP/MSM-12-Musaferpur (Figure 14), hosted in field.

Referred specimens: Two tracks from type area (GSP/MSM-13-Musaferpur, GSP/MSM-14-Musaferpur) (Figure 14), and a partial trackway from Moharian [24].

Locality, horizon and age: The holotype and two referred tracks found from Sor Muzghai ichnosite ( $\left.30^{\circ} 57^{\prime} 36^{\prime \prime} \mathrm{N} ; 6^{\circ} 08^{\prime} 24^{\prime \prime} \mathrm{E}\right)$, Musafarpur area, Qila Saifullah district, Zhob. Horizon is Vitakri Formation (upper part of Pab Formation). Its age is Maastrichtian [4]. Other referred partial trackway from Moharian (Salt Range), north of Quidabad town which is located between Khoshab and Mianwali cities of Punjab (Figure 1 of [24]). Horizon is Samana Suk limestone. Its age is Late Jurassic.

Etymology: Genus Anmol, Urdu for precious or not purchased, and pakhi, Saraiki for flying birds, and per, Saraiki for foot. Species $A$. alleni is after Mr. Nicholas Allen British Journalist which helped a lot for preservation of Sor Muzghai ichnosite.

Diagnosis and comparison: Itwas diagnosed as relatively narrow and elongated footprints. Its holotypic footprints are about $20-30 \mathrm{~cm}$ long and $8-10 \mathrm{~cm}$ wide representing left fore limb and right hind limb footprints. Footprints are parallel with each other resemble pterosaur tracks from South Korea. It was described in 2019 [6].

\section{Conclusion}

Most of the Mesozoic vertebrates discovered from Pakistan were formally described in August 2021 [6]. The remaining Mesozoic, and Cenozoic biotas found from Pakistan are formally being described here.

\section{Acknowledgements}

This work is a contribution to the Geological Survey of Pakistan.

\section{Conflicts of Interest}

The author declares no conflicts of interest regarding the publication of this paper.

\section{References}

[1] Malkani, M.S. (2021) Jurassic-Cretaceous and Cretaceous-Paleogene Transitions and Mesozoic Vertebrates from Pakistan. Open Journal of Geology, 11, 448-489. https://doi.org/10.4236/ojg.2021.118016

[2] Malkani, M.S. (2020) First Skull of Medium Sized Titanosaur from Indo-Pakistan Subcontinent Found from the Latest Maastrichtian Vitakri Formation of Pakistan; Associated Cranial and Postcranial Skeletons of Gspsaurus pakistani (Poripuchia, Stocky Titanosauria, Sauropoda) from Pakistan and India. Open Journal of Geology, 10, 448-489. https://doi.org/10.4236/ojg.2020.104020

[3] Malkani, M.S. (2020) First Snout with Complete Teeth Row of Titanosaur from In- 
do-Pakistan Subcontinent Found from the Latest Maastrichtian Vitakri Formation of Pakistan; Associated Cranial and Postcranial Skeletons of Saraikimasoom vitakri (Poripuchia, Stocky Titanosauria, Sauropoda) from Pakistan and Referred Fossils from India. Open Journal of Geology, 10, 368-407.

https://doi.org/10.4236/ojg.2020.104018

[4] Malkani, M.S. (2020) Pakisaurus balochistani (Poripuchia, Slender Titanosauria, Sauropoda) Associated Skeletons from the Latest Maastrichtian Vitakri Formation of Pakistan and Referred Fossils from India; Filling of Significant Missing Links of Isisaurus colberti (Poripuchia, Slender Titanosauria, Sauropoda) Found from $\mathrm{Pa}$ kistan. Open Journal of Geology, 10, 408-447.

https://doi.org/10.4236/ojg.2020.104019

[5] Malkani, M.S. (2020) Theropods, Mesoeucrocodiles and Pterosaurs Found from the Latest Maastrichtian Vitakri Formation of Balochistan, Pakistan; Description with Large Photographs and Comparison with Coeval Taxa from Indo-Pakistan Subcontinent. Open Journal of Geology, 10, 510-551.

https://doi.org/10.4236/ojg.2020.105023

[6] Malkani, M.S. (2019) Recently Discovered Basilosaurid, Baluchithere Rhinoceros, Horses, Sea Cow, Proboscidean, Eucrocodile, Pterosaurs, Plesiosaur, Fishes, Invertebrates and Wood Fossils, Tracks and Trackways of Dinosaurs from Pakistan; Comparison of Recognized Four Titanosaur Taxa of Indo-Pakistan with Madagascar. Open Journal of Geology, 9, 919-955. https://doi.org/10.4236/ojg.2019.912098

[7] Malkani, M.S. (2003) First Jurassic Dinosaur Fossils Found from Kirthar Range, Khuzdar District, Balochistan, Pakistan. Geological Bulletin, University of Peshawar, 36, 73-83.

[8] Malkani, M.S. (2009) New Balochisaurus (Balochisauridae, Titanosauria, Sauropoda) and Vitakridrinda (Theropoda) Remains from Pakistan. Sindh University Research Journal (Science Series), 41, 65-92.

[9] Malkani, M.S. (2004) Saurischian Dinosaurs from Late Cretaceous of Pakistan. Fifth Pakistan Geological Congress, Islamabad, 14-15 April 2004, 71-73.

[10] Malkani, M.S. (2003) Discovery of Partial Skull and Dentary of Titanosauria (Sauropod Dinosaur) from the Late Cretaceous Pab Formation of Vitakri Area, Barkhan District, Balochistan, Pakistan. Geological Bulletin, University of Peshawar, 36, 65-71.

[11] Malkani M.S. (2003) Pakistani Titanosauria; Are Armoured Dinosaurs? Geological Bulletin University of Peshawar, 36, 85-91.

[12] Malkani, M.S. (2006) Biodiversity of Saurischian Dinosaurs from the Latest Cretaceous Park of Pakistan. Journal of Applied and Emerging Sciences, 1, 108-140.

[13] Malkani, M.S. (2014) Titanosaurian Sauropod Dinosaurs from the Latest Cretaceous of Pakistan. 2nd Symposium of IGCP 608 "Cretaceous Ecosystem of Asia and Pacific", Tokyo, 4-6 September 2014, 108-111.

[14] Malkani, M.S. (2015) Titanosaurian Sauropod Dinosaurs from Pakistan. 12th Symposium on Mesozoic Terrestrial Ecosystems (MTE 12), and 3rd Symposium of International Geoscience Program (IGCP 608) Cretaceous Ecosystem of Asia and Pacific, Shenyang, 15-20 August 2015, 93-98.

[15] Malkani, M.S. (2015) Dinosaurs, Mesoeucrocodiles, Pterosaurs, New Fauna and Flora from Pakistan. Geological Survey of Pakistan, Quetta, Information Release No. $823,1-32$.

[16] Malkani, M.S. (2010) Updated Stratigraphy and Mineral Potential of Sulaiman (Middle Indus) Basin, Pakistan. Sindh University Research Journal (Science Series), 
42, 39-66.

[17] Malkani, M.S. (2006) Lithofacies and Lateral Extension of Latest Cretaceous Dinosaur Beds from Sulaiman Foldbelt, Pakistan. Sindh University Research Journal (Science Series), 38, 1-32.

[18] Malkani, M.S. (2008) Marisaurus (Balochisauridae, Titanosauria) Remains from the Latest Cretaceous of Pakistan. Sindh University Research Journal (Science Series), 40, 55-78.

[19] Malkani, M.S. (2010) New Pakisaurus (Pakisauridae, Titanosauria, Sauropoda) Remains, and Cretaceous Tertiary (K-T) Boundary from Pakistan. Sindh University Research Journal (Science Series), 42, 39-64.

[20] Wilson, J.A., Malkani, M.S. and Gingerich, P.D. (2001) New Crocodyliform (Reptilia, Mesoeucrocodylia) form the Upper Cretaceous Pab Formation of Vitakri, Balochistan (Pakistan). Contributions from Museum of Paleontology, University of Michigan, 30, 321-336.

[21] Malkani, M.S., Dhanotr, M.S.I., Latif, A. and Saeed, H.M. (2013) New Remains of Basilosauridae-The Giant Basal Whale, and Baluchithere-The Giant Rhinoceros Discovered from Balochistan Province (Pakistan). Sindh University Research Journal (Science Series), 45, 177-188.

[22] Malkani, M.S. (2007) Trackways Evidence of Sauropod Dinosaurs Confronted by a Theropod Found from Middle Jurassic Samana Suk Limestone of Pakistan. Sindh University Research Journal (Science Series), 39, 1-14.

[23] Malkani, M.S., Somro, N. and Arif, S.J. (2018) A New Pes Footprint of Sauropod Dinosaur Discovered from the Latest Cretaceous of Pakistan. Researchgate.net, Research, $1 \mathrm{p}$.

[24] Nizami, A.R. and Fahim, M. (2015) The Discovery of Ichno-Fossils of the Middle Jurassic Dinosaurs in the Central Salt Range, District Khoshab, Punjab, Sub-Himalayas, Pakistan. Punjab University Journal of Zoology, 30, 37-41. 